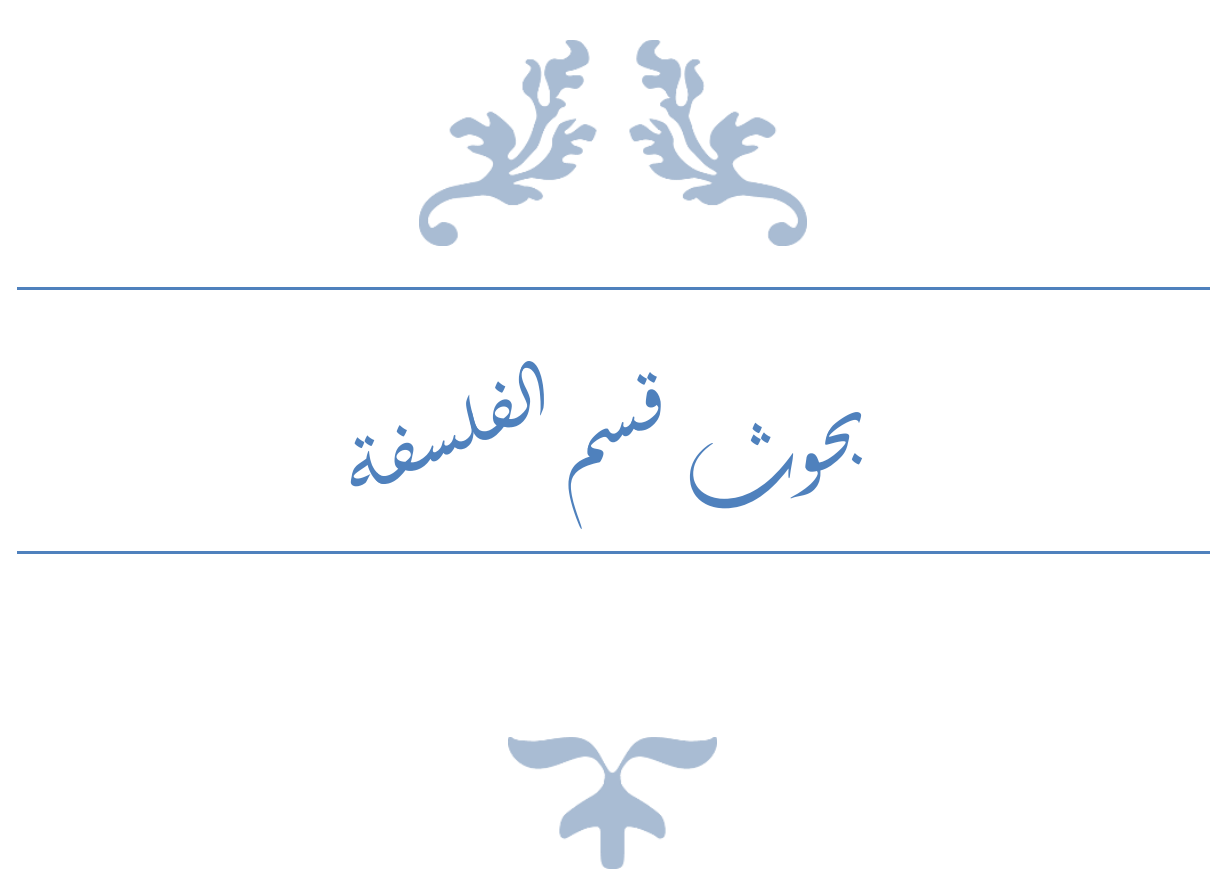




\section{موقف محمود قاسم من التراث والعولمة الغربية}

الباحث/أيمن محمود سيد أحمد محمد خليل

المعيد جامعة الأزهر الشريف

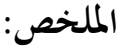

اهتم الدكتور محمود قاسم بمنهجية المقارنة والنقد والتحليل لفلاسفة اليونان والعرب في مختلف العصور الفلسفية وحتى عصر الحداثة وما بعدها، كما فعل مع ابن رشد وآند والأكويني،

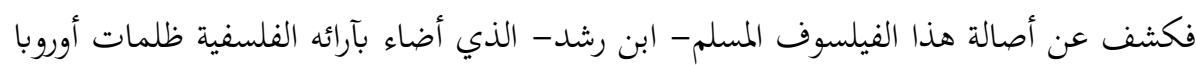

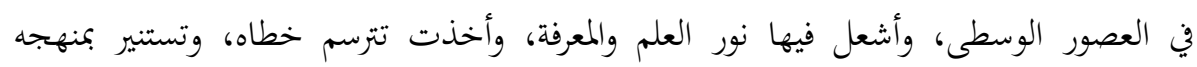

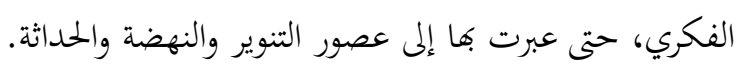

كان قاسم واعيا في تحليله، دقيقا في مقارناته، بصيرا في نقده، فلم يأت قاسم بالبديع من

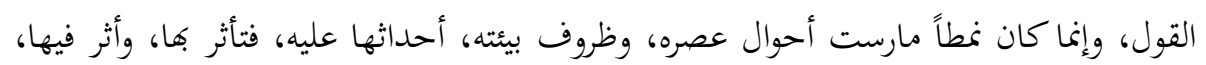
إذ أن الإنسان الواعي يتأثر بظروف العصر، ويؤثر فيها، وهي سنة إلهية.

وكان منهجه الموضوعي أساسا لأفكاره ومبادئه وآرائه الفلسفية وغيرها؛ فلم يكن قاسم

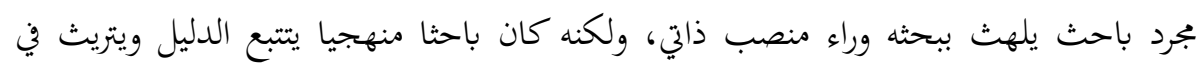

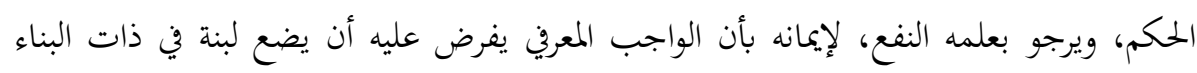

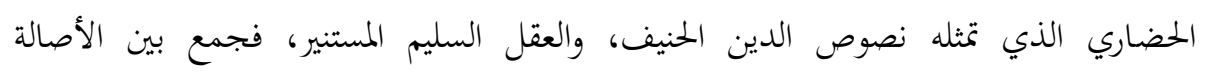
والمعاصرة.

فأثبت قاسم بالدليل أن توما الاكويني- ومن سار على شاكلته- لم ينهج فه العلماء في دراسته لفلسفة ابن رشد، وإنما وقف من فلسفته موقفا جد عجيب وغريب، ولا ينبئ عن روح

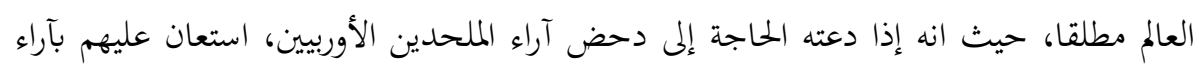

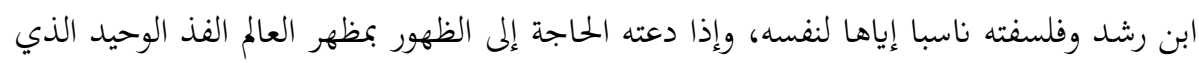




كلية الآداب والعلوم الإنسانية

حارب الإلحاد في عصره، عمد إلى وصف ابن رشد بأنه إمام الزائغين، وقام بتحريف آرائه الفلسفية والدينية.

Dr. Mahmoud Qassem was interested in the methodology of comparison, criticism and analysis of greek and Arab philosophers in various philosophical eras until the age of modernity and beyond, as he did with Ibn Rushd and Aquinas, revealing the authenticity of this Muslim philosopher Ibn Rushd, whose philosophical views illuminated the darkness of Medieval Europe, lit up the light of science and knowledge, and began to draw his steps, and enlighten his intellectual approach, until it crossed into the ages of enlightenment, renaissance and modernity.

Qassim was conscious in his analysis, accurate in his comparisons, insightful in his criticism, and Qassim did not come to the fore from saying, but it was a pattern that practiced the conditions of his time, the circumstances of his environment, its events on him, influenced it, and influenced it, as the conscious man is influenced by the circumstances of the times, and influences them, which is a divine year. His objective approach was the basis for his ideas, principles, philosophical opinions, etc.; Qasim was not just a researcher who gasped for his research behind a subjective position, but he was a systematic researcher who followed the guide and waited for judgment, and begged for his knowledge of benefit, because he believed that cognitive duty required him 
to put a brick in the same civilized structure represented by the texts of religion and enlightened common sense, combining originality and contemporary.

Qassem proved with evidence that Thomas Aquinas, who followed his example, did not take the approach of scholars in his study of ibn Rushd's philosophy, but stood from his philosophy a very strange and strange attitude, and does not speak of the spirit of the world at all, since if the need to refute the opinions of European atheists, who used ibn Rushd's opinions and philosophy to give it to himself, and if he needed to appear as the only brilliant world that fought atheism of his time, he described Ibn Rushd as the imam of the jewelers, and distorted his philosophical and religious views.

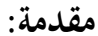

مفهوم كلمة التراث: التراث في العربية أصله ورث ووراث وأبدلت الواو تاء فصارت تراثًا،

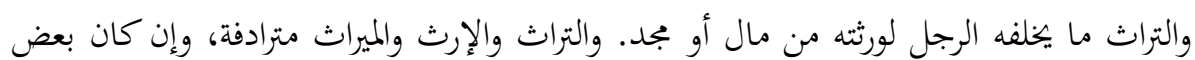

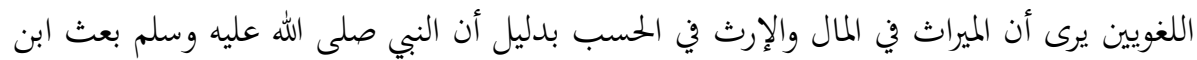

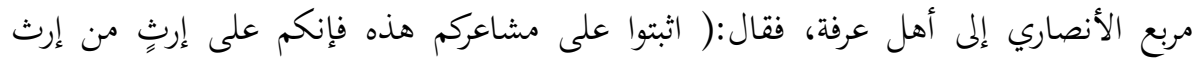

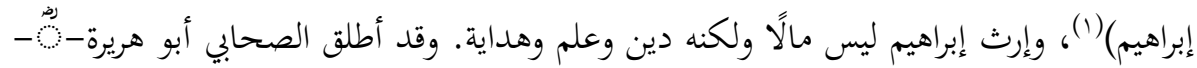

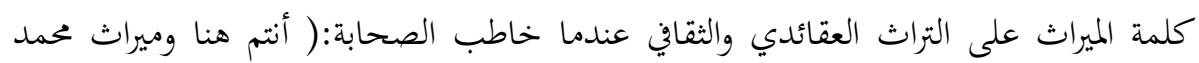

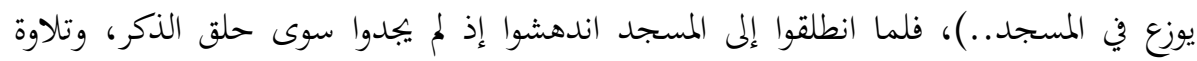

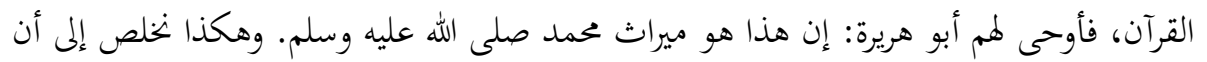


التراث في لغة العرب بمعنى الميراث ويطلق على وراثة المال والعقيدة والدين والمجد والحسب(r). وعلى ميراث كل شىء.

ولا يوجد هناك تعريف خاص بالتراث في الاصطلاح، ولكن هناك تعريفات كثيرة عن

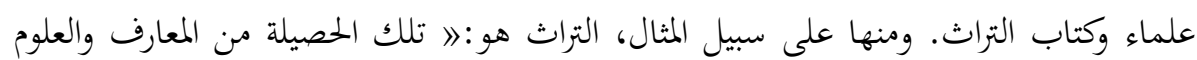
والعادات والفنون والآداب والمنجزات المادية التي تراكمت عبر التاريخ. وهو نتاج جهد إنساني متواصل قامت به جموع الأمة عبر التاريخ، وعبر التعاقب الزمني أصبحت هذه واته الحصيلة المسماة

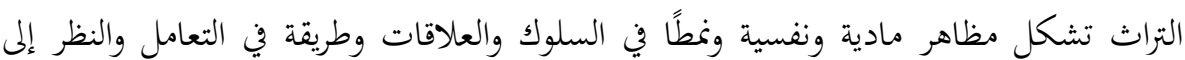

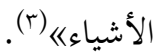

إن كل تراث عدا العقيدة السماوية، هو: بمثابة نتاج فكري بشري، يحمله السلف إلى الخلف، ويتضمن في داخله: الأفكار والأفعال، السلبيات والإيجابيات، الصحيح والخطأ. فالتراث ركن جوهري من أركان الهوية الثقافية للأمم، ومكون من مكوناهما الفكرية والسلوكية والوجدانية؛

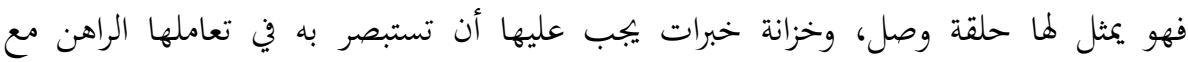

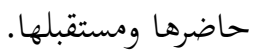

هذا، ولقد عمل محمود قاسم جاهدًا طوال حياته على إحياء التراث العربي بكل ما أوتي

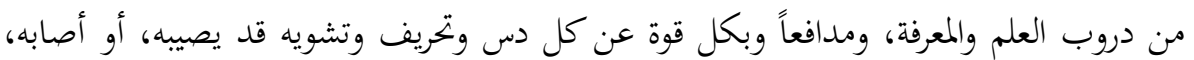

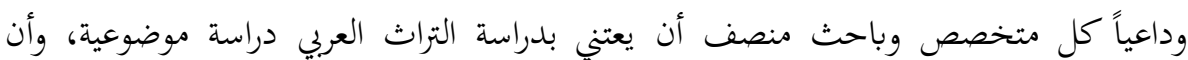
يعرضه في صورة جديدة نقية، وأن يحرره من الرواسب الدخيلة عليه.

ففى مجال تحقيق التراث العربي، نجد أن قاسما قد حقق لابن رشد كتابه" مناهج الأدلة في عقائد الملة"، كما حقق الجزء الخامس عشر من كتاب" المغني" للقاضى عبدالجبار أحد أئمة المعتزلة وحقق كذلك جزء" الطبيعيات من كتاب الشفاء" لابن سينا.

وفي سبيل إحياء التراث العربي حاول قاسم وبكل شجاعة وقوة أن ينتصر لأعلام الفكر

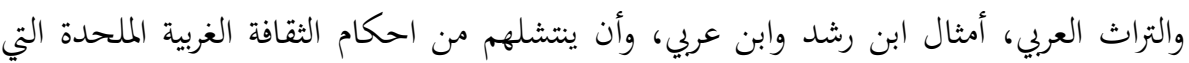

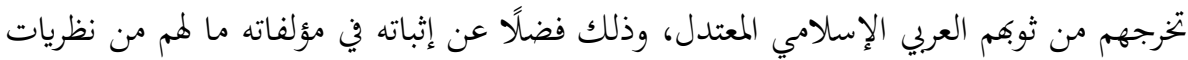


معرفية ورؤى علمية دقيقة نافعة قد نُسِبَت إلى غيرهم من الغربيين بالسطو، فالأمر نجده كأن

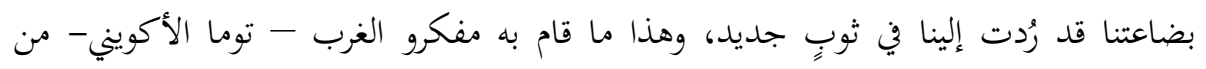

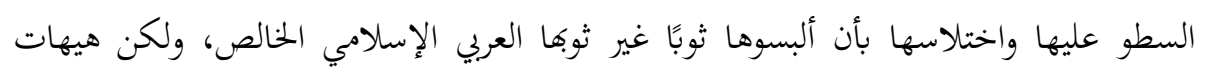

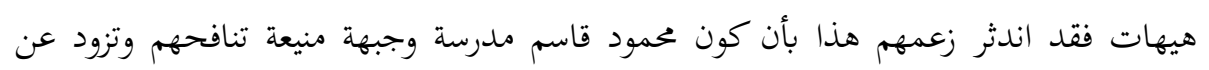

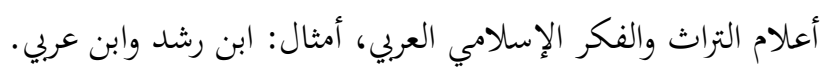

\section{أولاً: موقف قاسم من التراث الغربي:}

التراث الغربي: كلمة شاملة عامة، وتشمل العلم والدين والفلسفة، ويشمل العلم

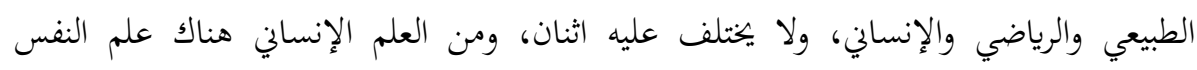

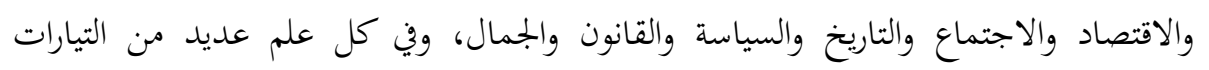

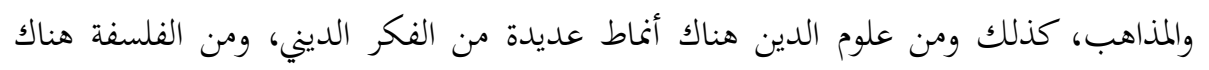

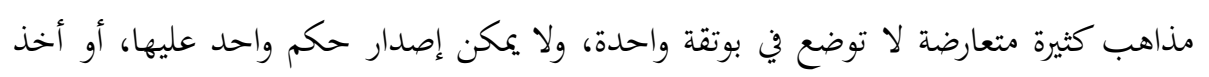

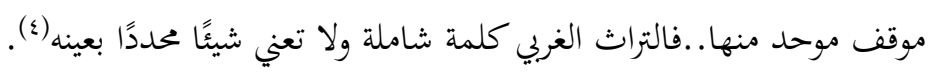

والتراث معنى شامل لكل ما هو موروث من ثقافات تشتمل على قيم، وتقاليد،

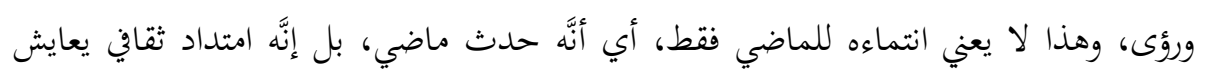

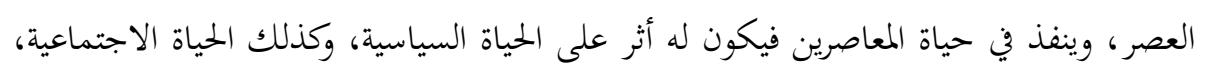

والثقافية، إلى جانب الحياة الروحية، والتعامل مع البيئة المحيطة بهام(ه).

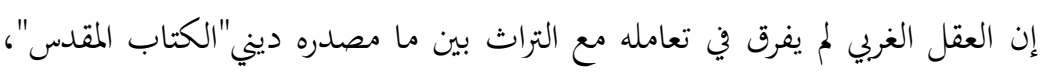

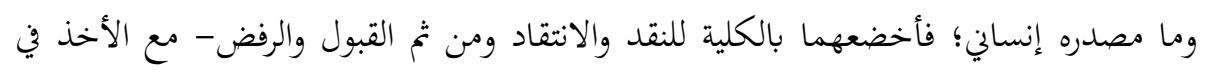

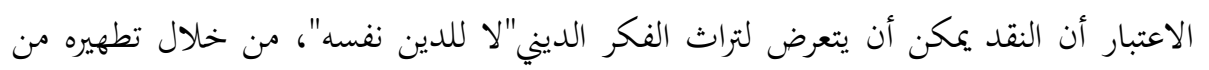

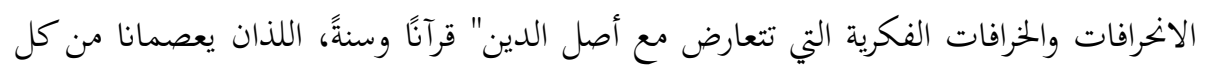

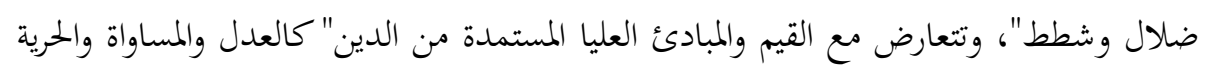

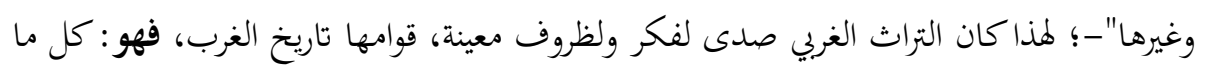

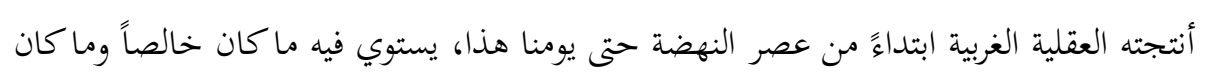
مقتبساً، صار موجوداً أو داخل تلك العقلية. 
وإذا نظرنا إلى موقف محمود قاسم من التراث الغربي الفلسفي: نلمح في المقدمة،

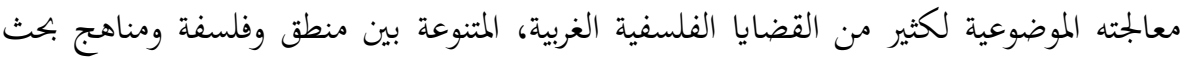

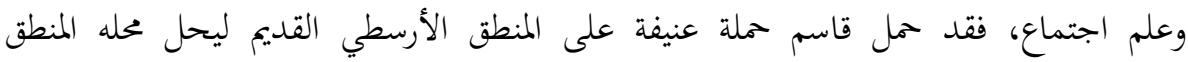

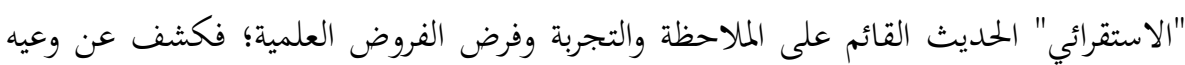

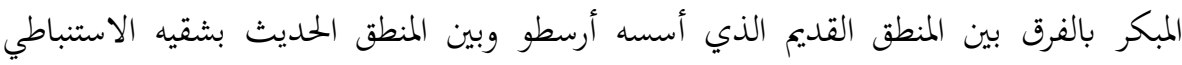

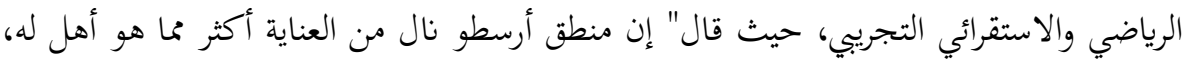

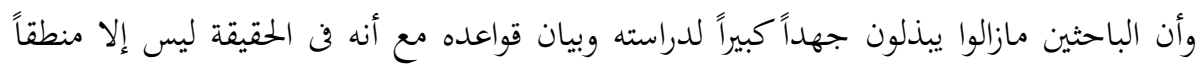

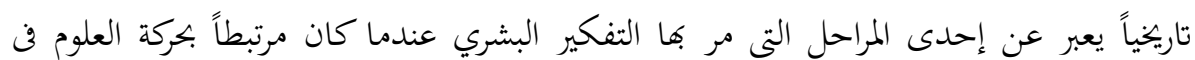

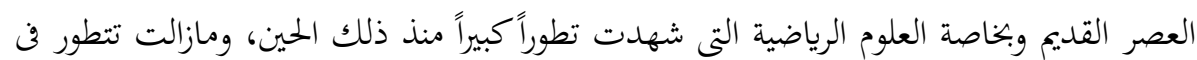

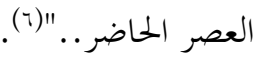

ثم اختتم قاسم هذه الفقرة بما يؤكد وعيه بأهمية الربط بين المنطق ومناهج البحث التجريبية

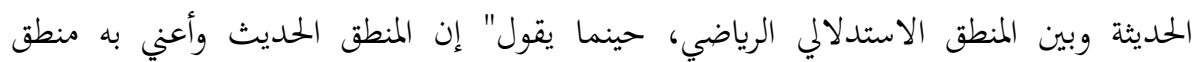

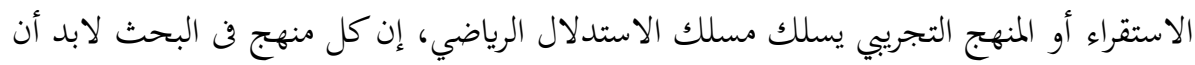

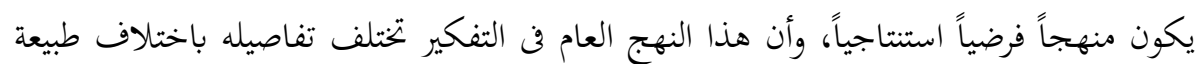
الموضوعات التي يعالجها في مختلف العلوم" (v).

ونلمح أيضاً إشارة قاسم إلى أنه قد وجد في دراسته للأكويني وليبنتز وجان جاك رسو تأثرًاً

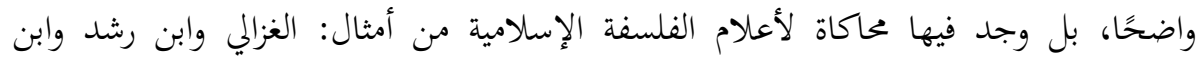
(^) عربي

ولنضرب مثالاً، بفقيهنا المالكي وفيلسوفنا العقلاني"ابن رشد-ت 90 هـ" والفيلسوف

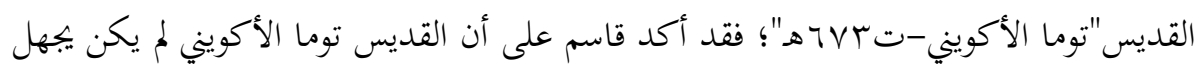
فلسفة ابن رشد؛ حيث استطاع الأكويني أن يستغل نظريات الفيلسوف القرطبي، سواء ما كان اندان

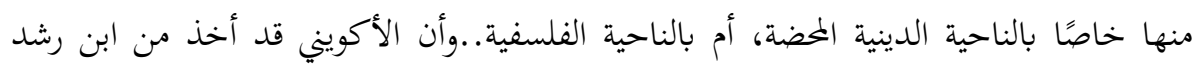

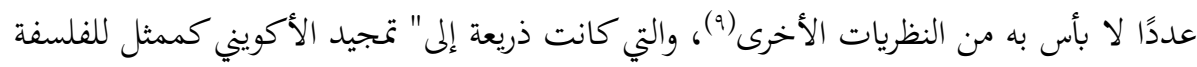

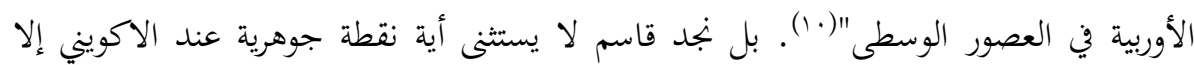


ويرجعها إلى أصلها عند ابن رشد، ولا يختلف الحال هنا في نظرية المعرفة بينهما، تلك النظرية التي قصد بما العلم الإلهي عند كليهما (1).

ودلل قاسم على أنه ليس بصحيح أن توما الاكويني قد خالف ابن رشد في نظريته الخاصة

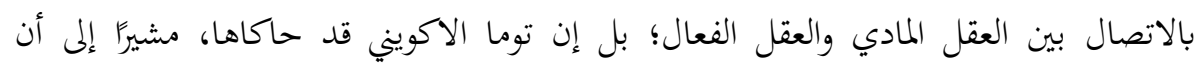

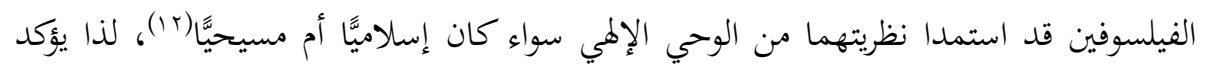

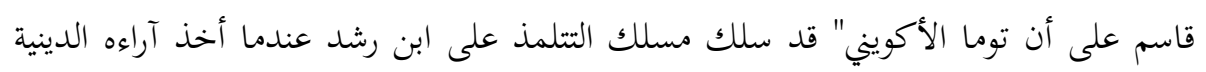

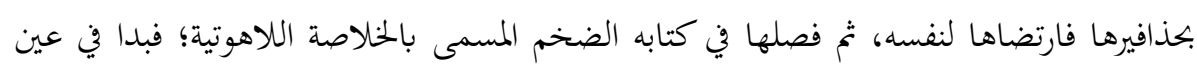

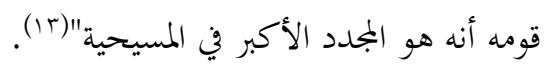

كما نلمح أيضاً مواجهة قاسم للهجمات الاستشراقية الشرسة التي تبناها الطاعنون،

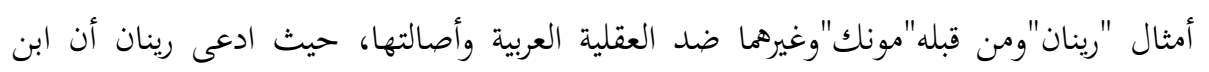

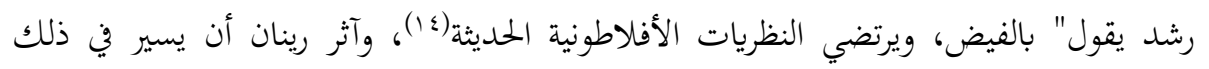

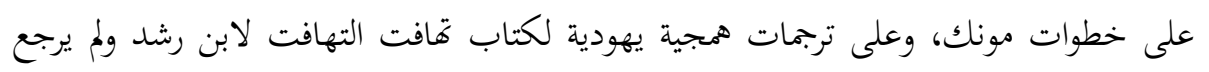
للنصوص الأصلية(10).

فثار قاسم وأثبت على أن رينان قد أخطأ فهم ابن رشد وهضمه حقه، وخلط بينه وباقي

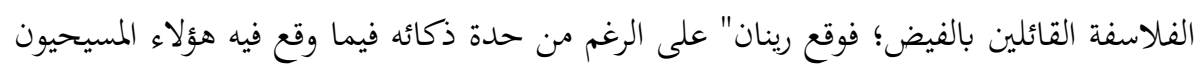

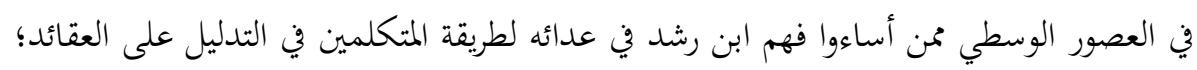

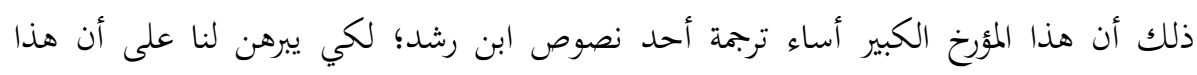

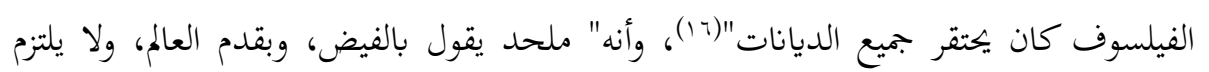
بوحي ولا دين" (iv).

ثم أشار قاسم إلى أن رينان لم يكن موضوعيا في دراسته لابن رشد،" السبب الرئيسي في

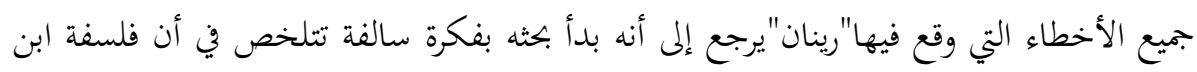
رشد لا تختلف في شئ عن فلسفة الفارابي وابن سينا"(1). 
كما أن رينان قد استمد هذه الفكرة من مونك، مع أنه كان في استطاعته أن ينصف ابن

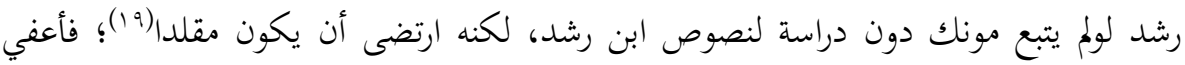

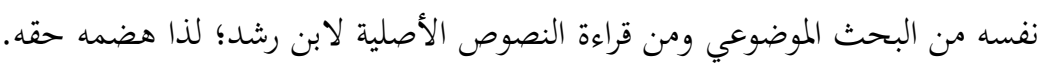

تم ينتقل قاسم ليؤكد علي أن فيلسوف قرطبة قد رفض نظرية الفيض في كتابه تافت

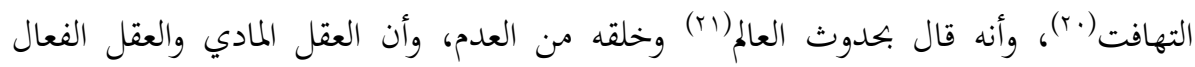

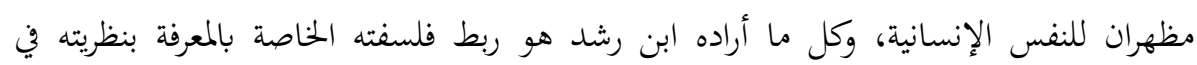

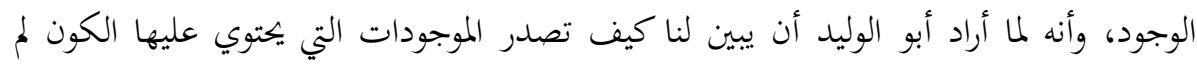

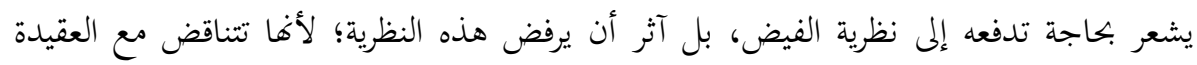

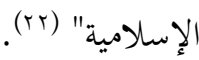

ويرى قاسم أها نظرية يمكن أن تنسب إلى الفارابي وابن سينا لا إلى ابن رشد، فيقول"وقد

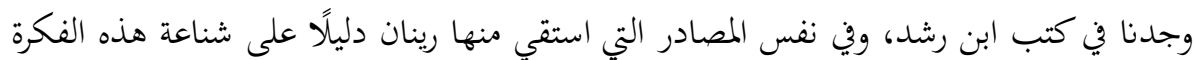

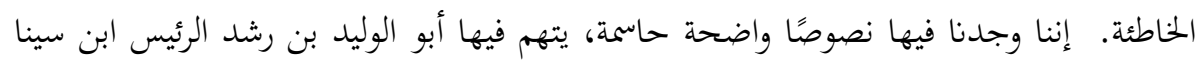

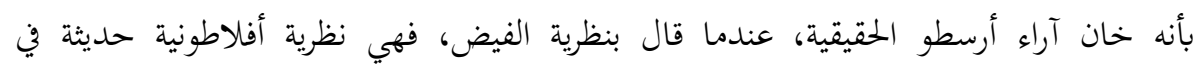

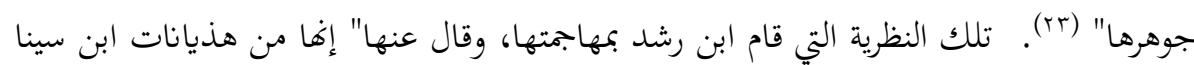

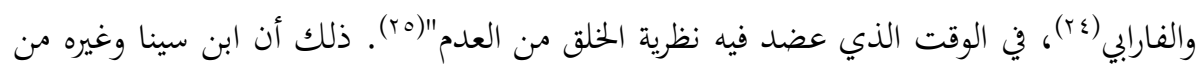

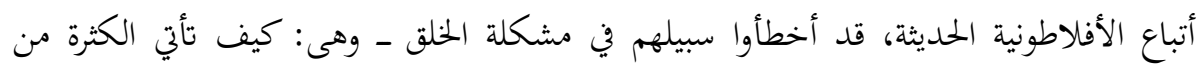

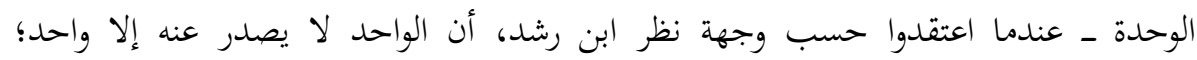

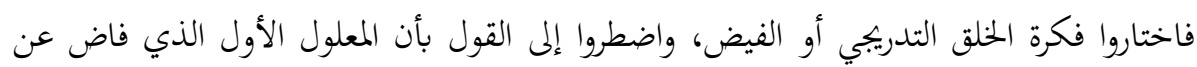

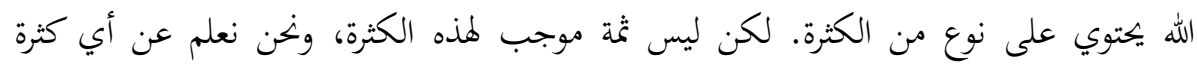

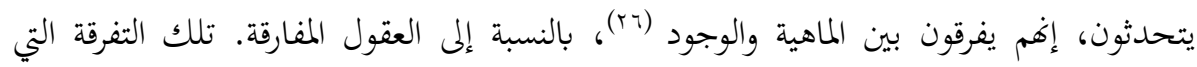

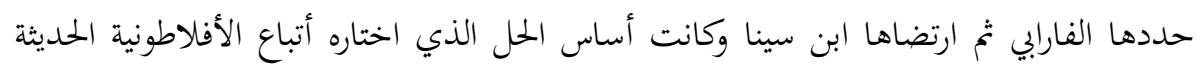
لمشكلة الفيض أو الخلق التدريجي (rV).

فقال ابن رشد ـ حسب قول قاسم - إن آراءهم منافية للفلسفة الحقة، ولا تقوم على

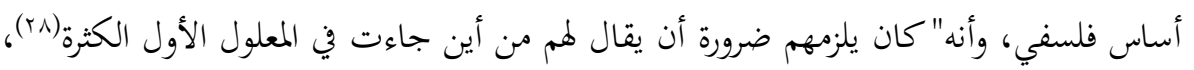


وكما يقولون أن الواحد لا يصدر عنه كثير. كذلك يلزمهم أن الكثير لا يصدر عن الواحد،

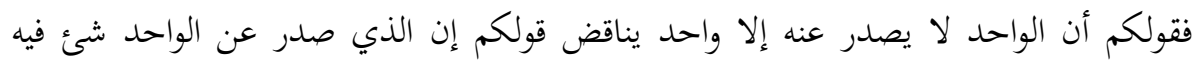
كثرة" (ra)

ثم تعجب ابن رشد من الخطأ البالغ الذي انقاد إليه ابن سينا في هذه المسألة، وأرجع ابن

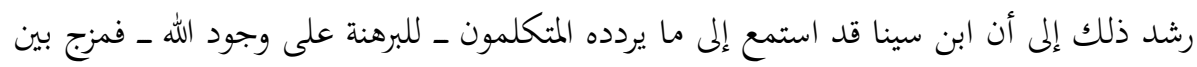

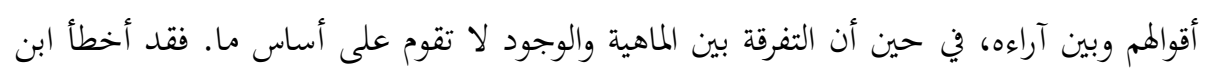

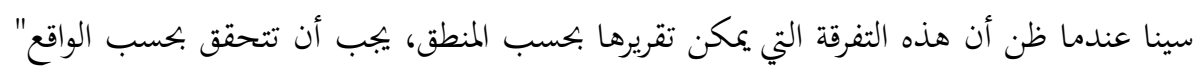

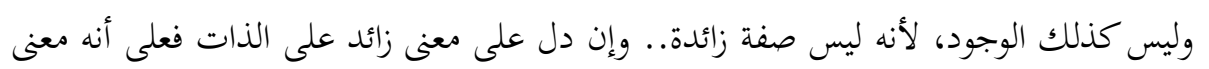

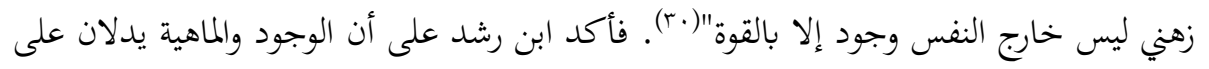

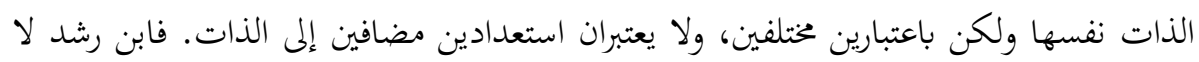

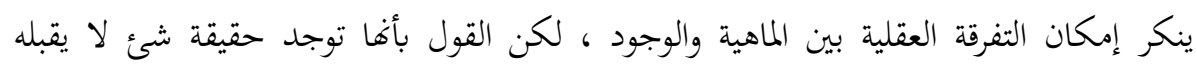

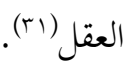

ومما لا شك فيه أنه" لا يمكن التسليم بنظرية الفيض إلا بشرط التسليم بالتفرقة بين الماهية

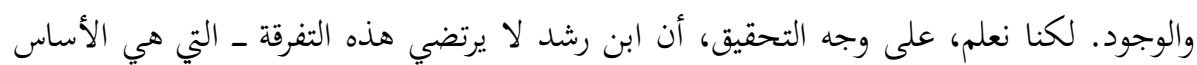

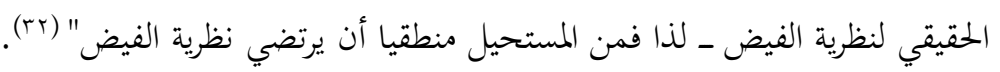

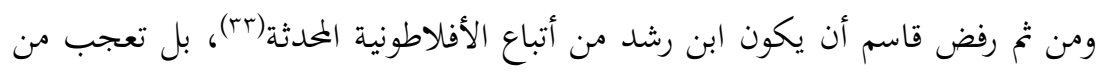

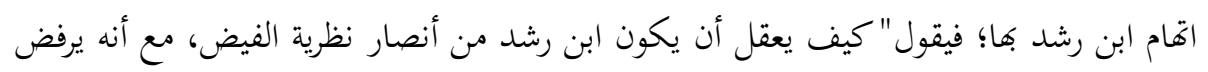
تفرقة ابن سينا بين الماهية والوجود"(؟r).

ثم أشار قاسم إلى أن ابن رشد قام" بهدم دليل المتكلمين الذي يعتمد على التفرقة بين

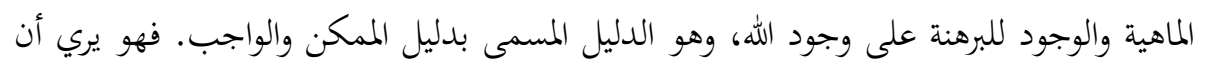

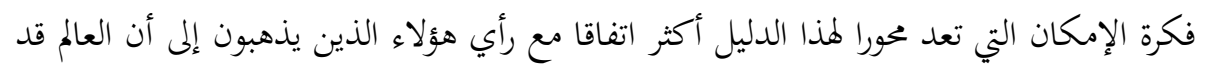

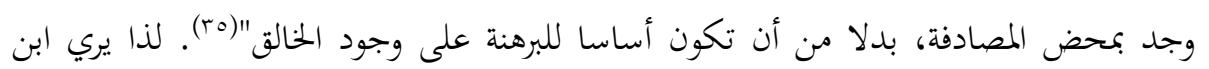
رشد في فاية الأمر أن نظريتهم في الفيض" ليست إلا خرافة وأسطورة "(rr). 
وقد أشار قاسم من جانبه إلى أن هذه النظرية تعد بمثابة صورة أو صدى خافت لفكرة

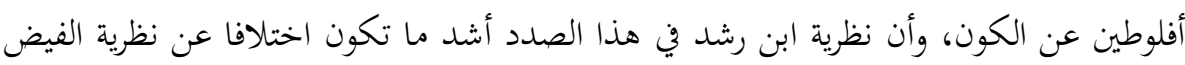

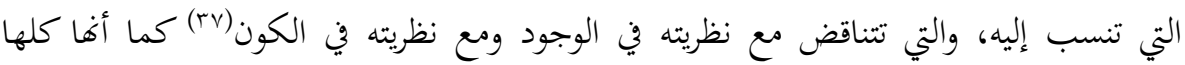

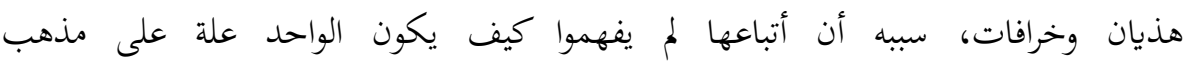
أرسطوطاليس(^^). والحق أها نظرية قد أفسدت علينا عقيدتنا الدينية وشوهت فكرنا الإسلامي.

وقد فسر قاسم سبب اتحام ابن رشد بهذه النظرية قائلاً" لقد اتخذ الملحدون في أوربا ابن

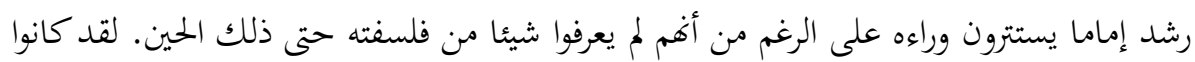

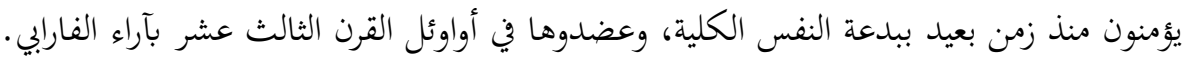

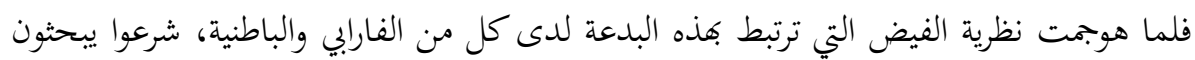

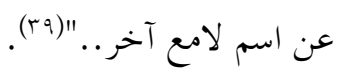

فراحوا يحشدون الأسماء اللامعة التي يُشهد لها بالاستنارة؛ التماسًا منهم للسبق، انتصارًا

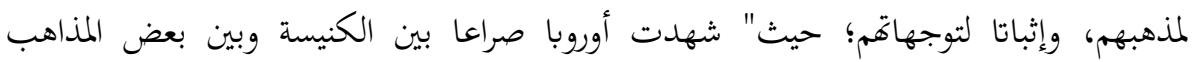

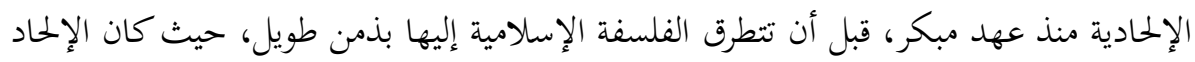

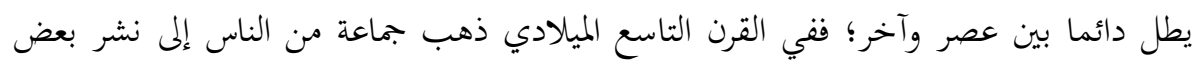

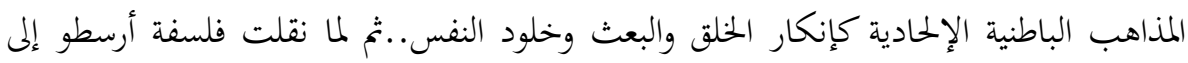

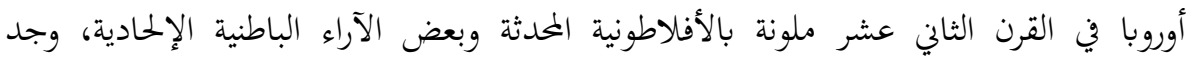

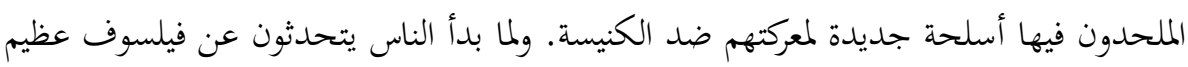

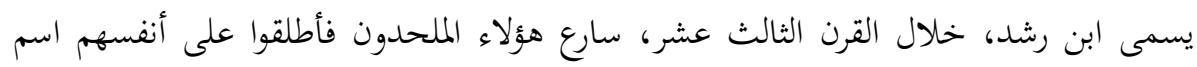

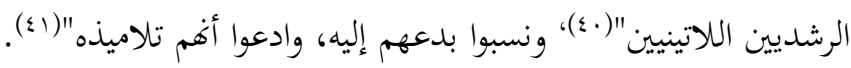

فنسب هؤلاء الملحدون إلحادهم إلى ابن رشد معتمدين على شروح ابن رشد ـ بدلا من

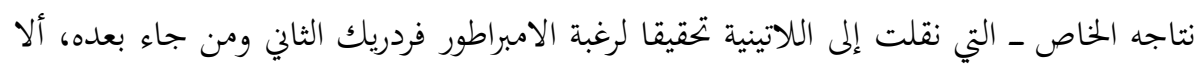

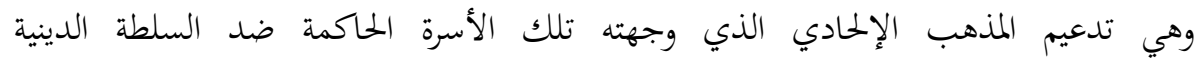
المسيحية(r) وعين. 
وهكذا جرت المقادير أن يصبح ابن رشد ضحية ذلك الصراع الديني في أوربا المسيحية خلال القرنين الثالث عشر والرابع عشر بصفة خاصة، وهما القرنان اللذان لم يكونا فترة إيمان عميق، كما يظن البعض؛ بل كانا فترة إلحاد وفوضى عقلية بالغة"(r؟).

ومن المستشرقين أيضاً الذين هاجموا ابن رشد دون وجه حق "ماندونيه" الذي " لما أراد

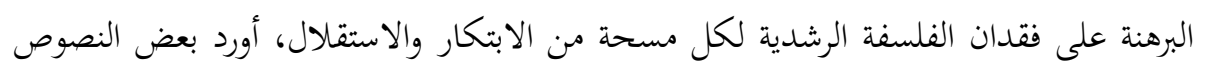

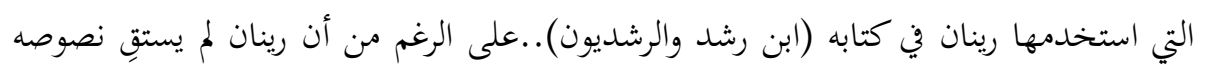
من المراجع الأصلية الوثيقة، وأن التراجم التي اعتمد عليها تتناقض مع النصوص الموثوق بها...-وقد اضطر مونك- إلى تعديل نص أساسي حتى يجعله على وفاق مع أسطورة خيالية خاطئة (ء؛).

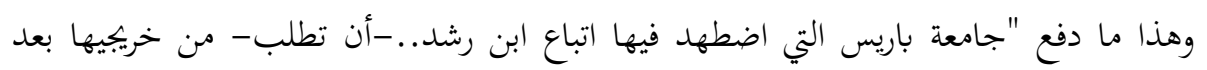
مضي قرن من الزمان أن يُقسموا غير حانثين الا يُعِلموا إلا الأشياء التي تتفق مع تعاليم أرسطو

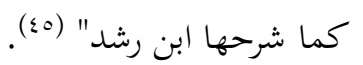

وواضح من النص أن أتباع ابن رشد- في أوروبا- تعرضوا للاضهاد أمداً طويلاً، ولا عجب في ذلك؛ لأن" أعداء الكنيسة كانوا، في ذلك الحين، تلامذة الفيلسوف العربي الأندلسي ابن رشد، وحوارييه، من أولئك الذين قرأوا، في استفاضة كتبه الموضوعية ولا سيما "قافت التهافت" وخصوصاً كتبه التي يشرح فيها أرسطو" (1ء).

وهكذا تصدى قاسم للهجمات الاستشراقية وموجات الافتراء التي تبناها رجال الفكر الغربي ضد العقلية العربية وأصالتها، وأعاد ابن رشد إلي تراثه الإسلامي الذي حاولوا أن يخرجوه .4 sis

وأود أن أشير إلى أن العقلية المسيحية بعد حالة الفراغ الفكري التي بدأت مع القرن الثاني عشر الميلادي قد باتت مهيَّة للانفتاح على الفلسفتين: الإسلامية واليهودية؛ مما أوجد ميدانًا عريضًا أمام النتاج الفكري الإسلامي، وساهم في ظهوره وترجمته وانتشاره، وخاصة النتاج الخاص بفيلسوف قرطبة"ابن رشد". 
فالعقل المسيحي الغربي" كان حتى القرن الحادي عشر لايفهم الا الفوز بالجنة، ومعرفة

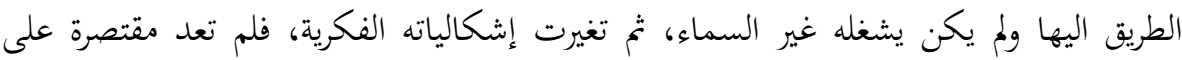

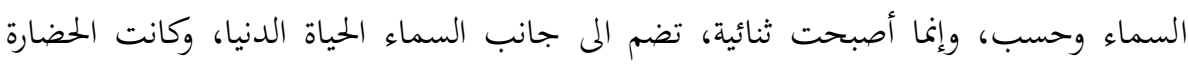
الإسلامية قد اجتهدت-من قبل- في تقديم حلول لهذه الإشكالية، وهذه الجهود قد اتضحت

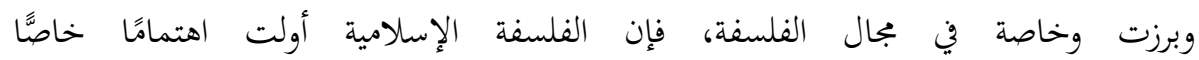

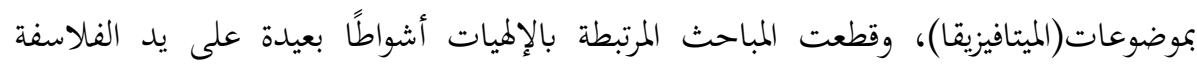

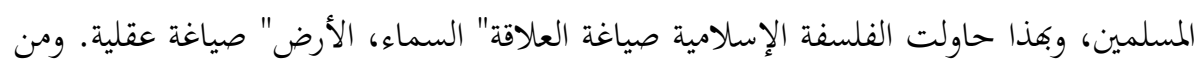

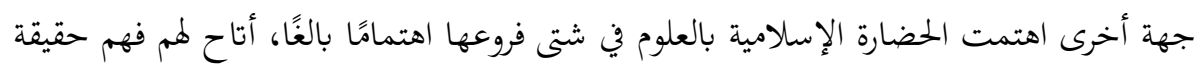

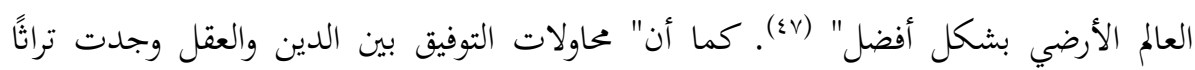

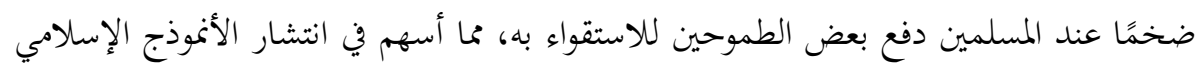
في العالم اللاتيني" (ఓ^)

وقد يفسر لنا النص السابق الخطوة المبدئية التي دعت العالم الغربي المسيحي - في ذلك الك الكان

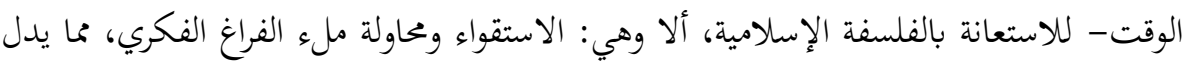

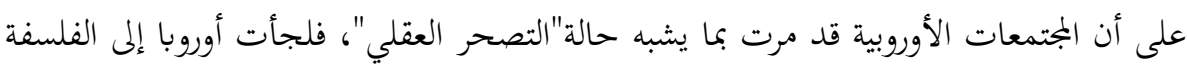

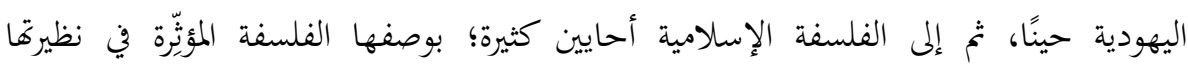

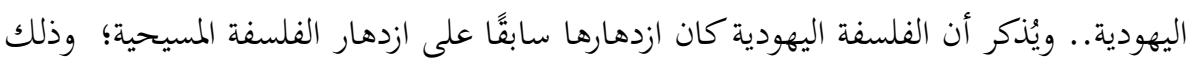

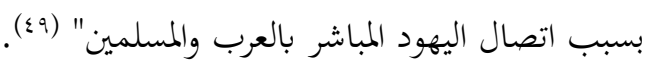

مما سبق حول موقف قاسم من التراث، والذي انتصر فيه للعقلية العربية وأشاد بتأثيرها في

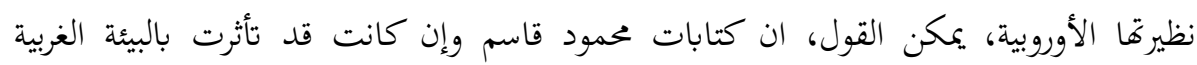

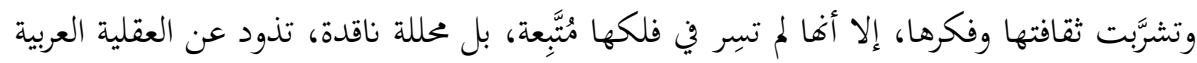

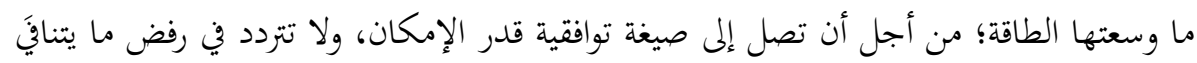
مع المرتكز الإسلامي الذي ترتكز عليه.

كما أن محمود قاسم وإن كان يذود عن نتاج العقلية العربية، إلا أننا نلمح في كتاباته

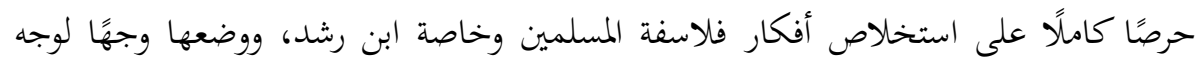


أمام الطاعنين فيها؛ بيانًا لأصالتها واستقلاليتها، خاصة وأن مذهبه الفكري يصطبغ بصبغة رشدية حتى النخاع.

لقد كان يرى في ابن رشد النموذج المثالي للفيلسوف المسلم الذي نبغ عقليًا وطور من

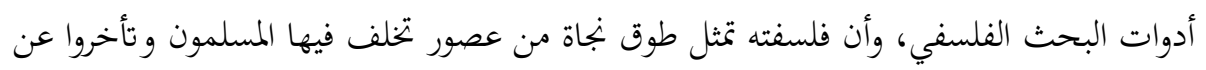

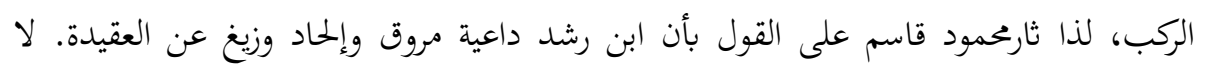

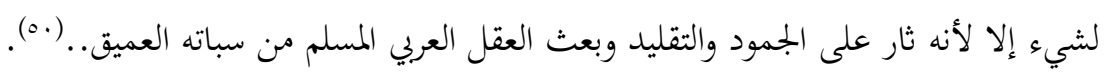
ومن ثم، أنشأ محمود قاسم، منهجًا جديدًا ومبتكرًا في استقراء الرجل بعيدًا عن مؤثرات

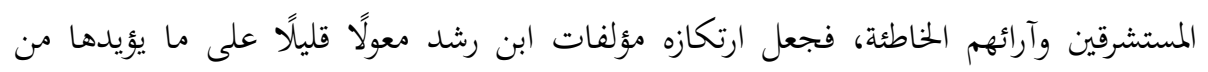

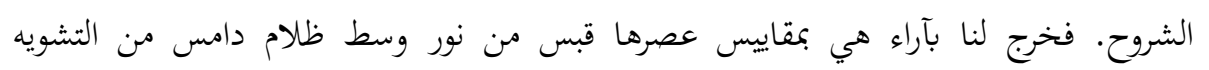

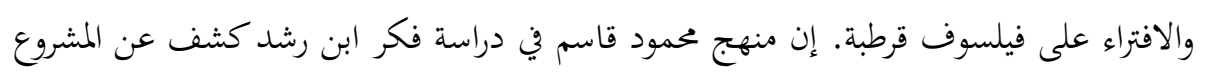

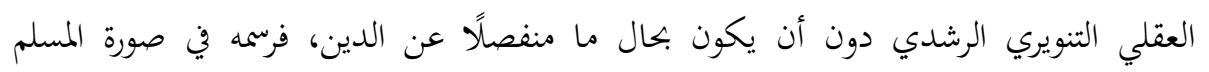
العقلاني، في الوقت الذي أراده فيه قوم آخرون أن يكون عقلانيًا ملحدًا (10.

هذا ابن رشد، محامي الفلاسفة، وتلميذ الفكر الإسلامي، الذي ابته ابتحاهًا عقليَّا منهجياً

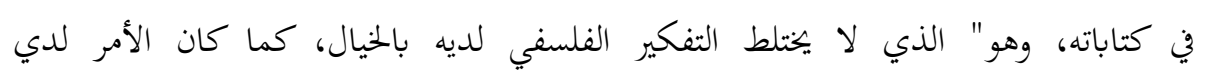

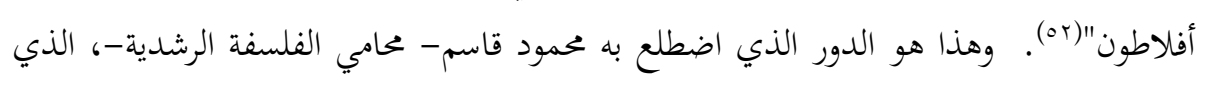

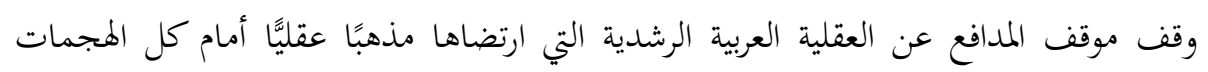

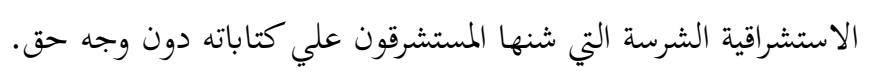

\section{ثانياً: موقف محمود قاسم من العولمة الغربية:}

العولمة: إذا أردنا أن نقف على مفهوم العولمة، فإن القارئ للكتابات العديدة والمختلفة،

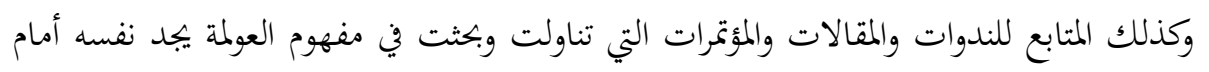

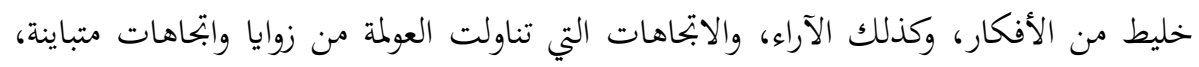

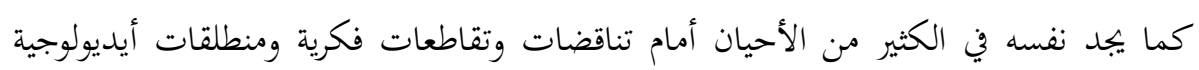
وأكاديمية تكون في بعض الاحيان متلاقية، وفي أحيان أخرى متنافرة ومتباعدة. 
إن مصطلح العولمة مصطلح جديد في طرحه الآن في هذه المرحلة، لكن التخطيط له

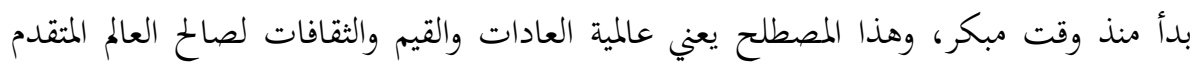
اقتصاديًا، وبمعنى أخر هي محاولة سيطرة قيم وعادات وثقافات العالم الغربي على بقية دول العالم،

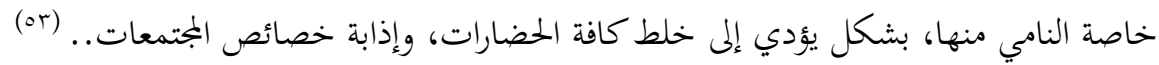
وقد عرَّف صادق العظم العولمة بأهَّا تعني"وصول نفط الإنتاج الرأسمالي إلى نقطة الانتقال

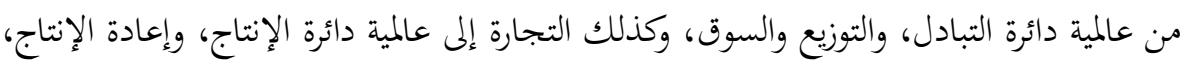

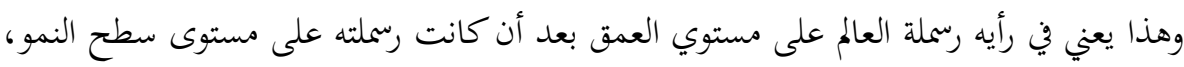

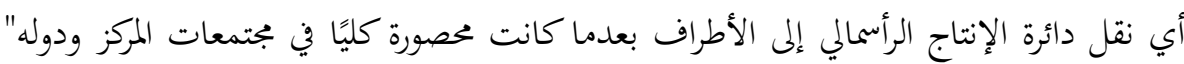

والعولمة" مشروع حضاري غربي متكامل البنيات، أوجده التلاقي بين التطلعات والحاجات

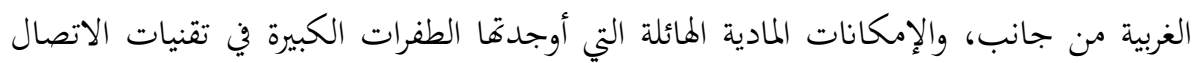

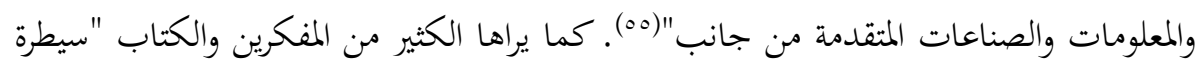

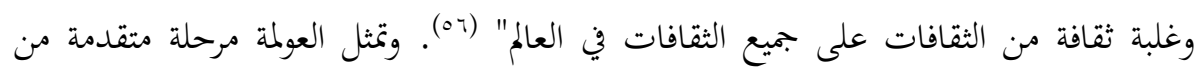
مراحل التاريخ الإنساني، المتطور دائمًا، من حيث تراكئ تراكم المعرفة العلمية والتكنولوجية التي لا يجيوز

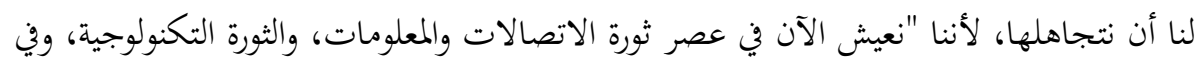

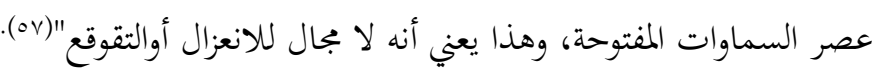

وقد عرَّف الكاتب الفرنسي "دولفين" العولمة بأََّّا: "تبادل شامل وإجمالي بين مختلف

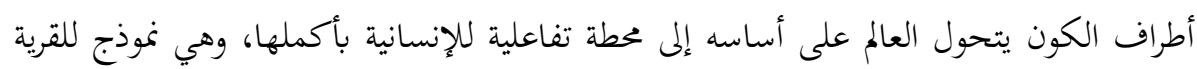

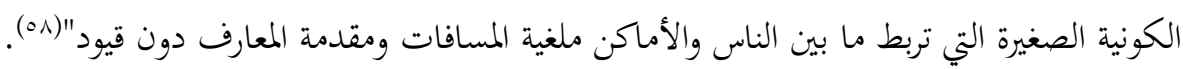
فالعولمة إذاً تحول دول العالم من دول متفرقة ومتعددة الجنسيات والثقافات، مغلقة على

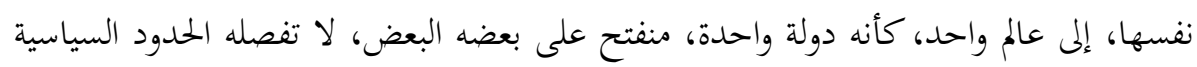
أو القيود القانونية. 
ويشير جون رالستون سول في كتابه (اغهيار العولمة وإعادة اختراع العالم)(هُمإلى أن من

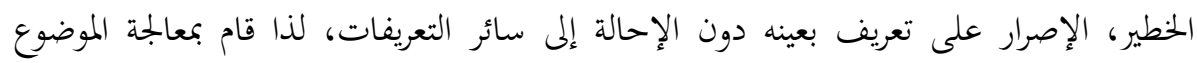

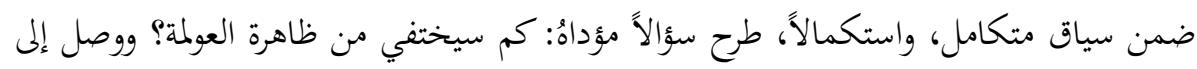

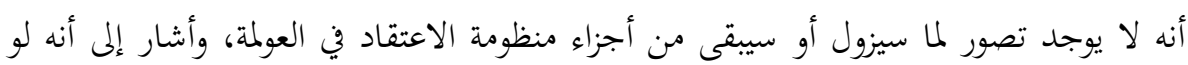

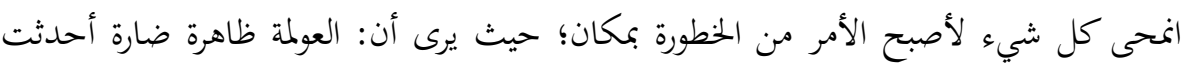

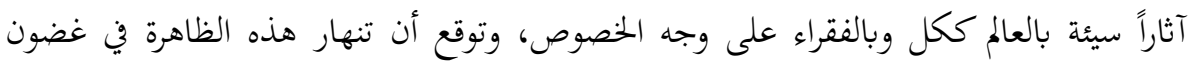

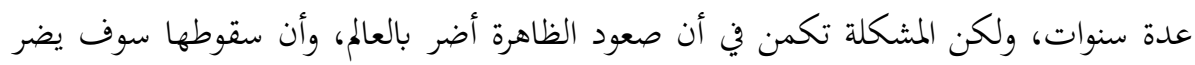

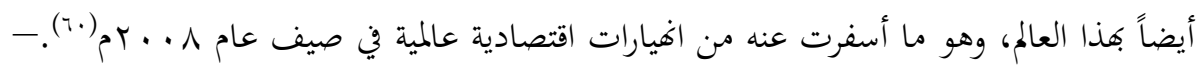

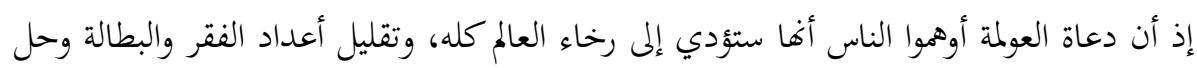

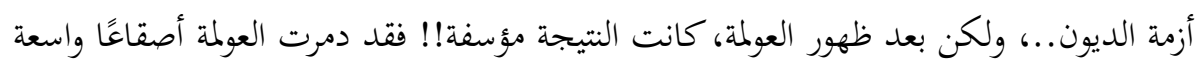

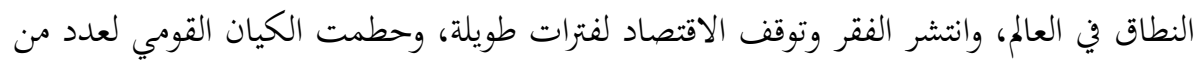

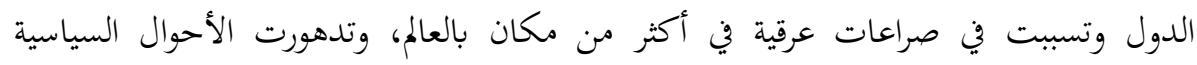

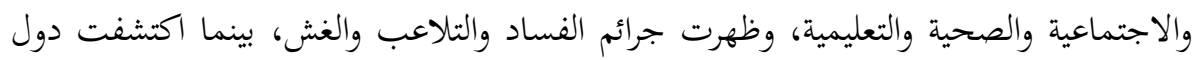

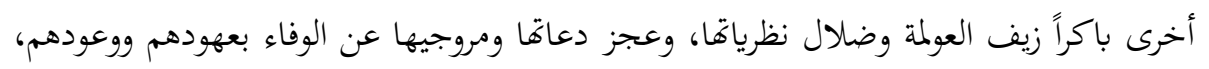

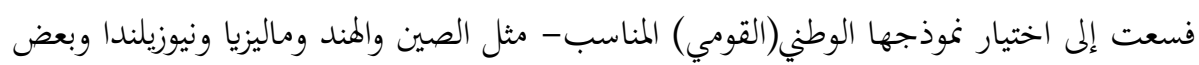

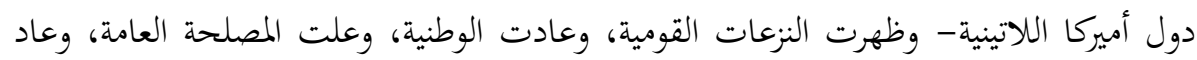

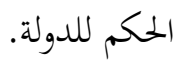

ومازال السؤال يطرح نفسه قديمًا وحديثًا حول العولمة ضد أو مع، ويشير الدكتور محمود

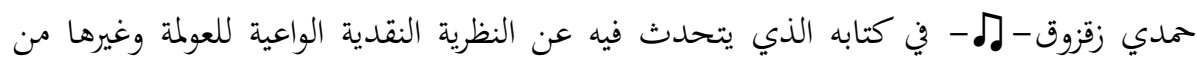

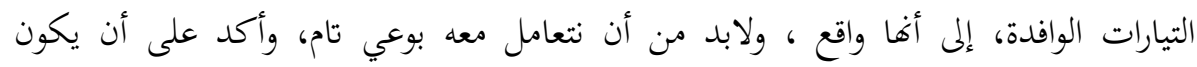

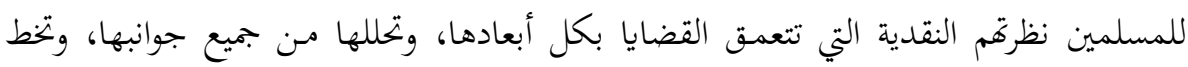

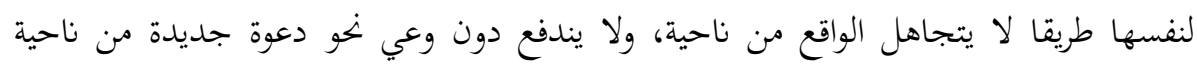

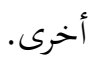

فالإسلام كدين ليس تياراً فكرياً أو ظاهرة وقتية حتى يخشى من التيارات الفكرية الوافدة،

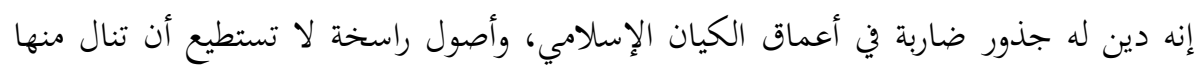


التيارات الوقتية الطارئة. ولا يخشى على هذا الدين من أية تيارات داخلية أو خارجية مهما كانت

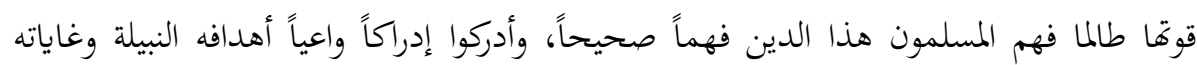
السامية وجوهره الحقيقي.

كما أن العولمة واقع لا يجدي معه أسلوب الرفض. إنه تيار بدأ بالبمال الاقتصادي - إلى

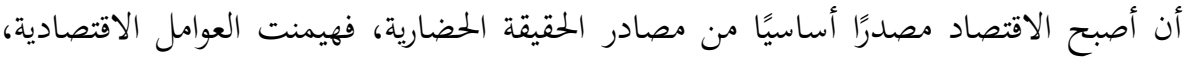

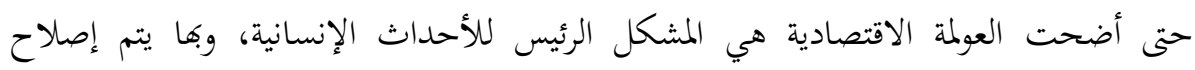

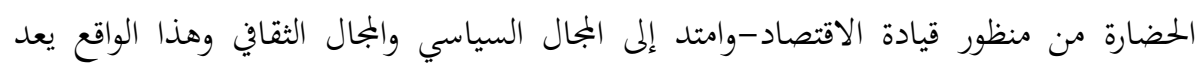
حقيقة ماثلة أمامنا لا بجال لإنكارها.

وإذا كانت العولمة تدف إلى إزالة الحواجز الزمانية والمكانية والثقافية والسياسية

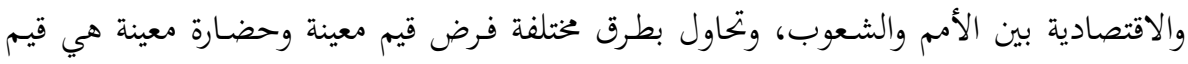

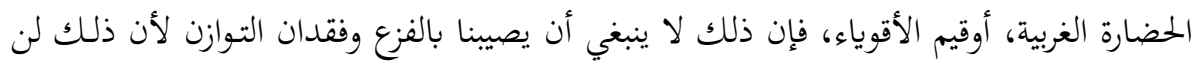

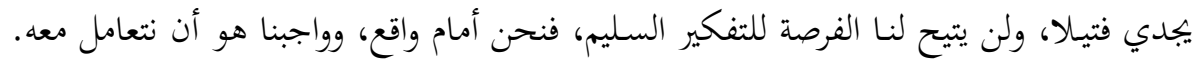
وهذا الواقع ليس كله شراً وليس كله خير، ومن هنا ينبغي التعامل معه على هذا الأساس (11). ولقد مرت علاقة الشرق بالغرب بفترات متنوعة، سواء من حيث التأثير والتأثر، أو طرق

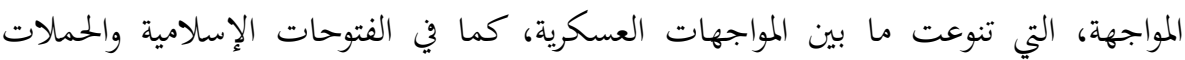

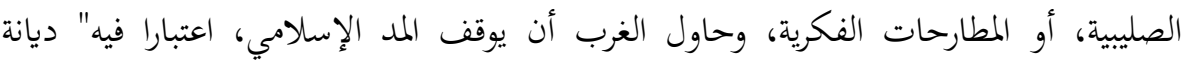

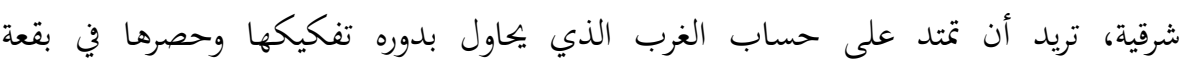

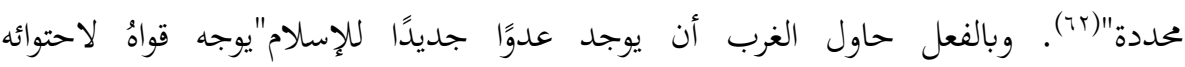

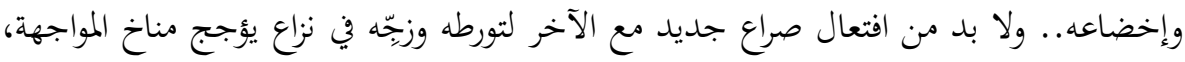

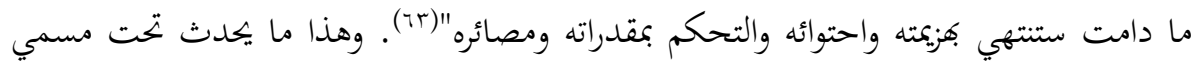

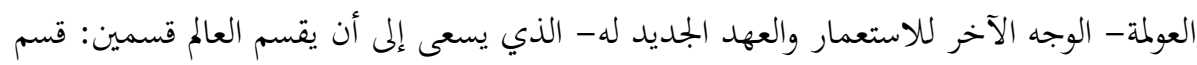

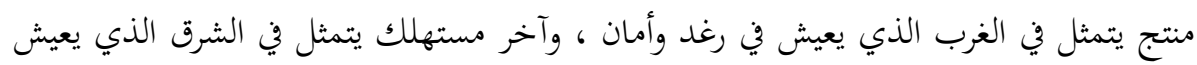
في قهر وغلبة أمر، رغم أن له الحق في العيش في أمان وسلام مشترك. 
موقف قاسم من العولمة: وكون العولمة تتصدر المشهد اليوم، وتعتبر الجناح الفكري للنظام

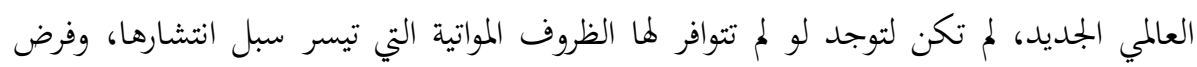

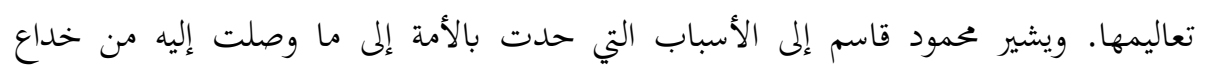
علموي، مرجعًا إياها إلى مايلي: المود فاسئ

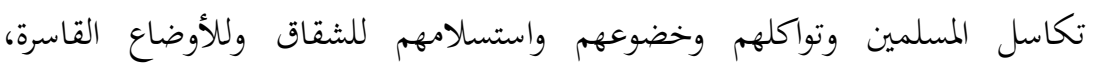

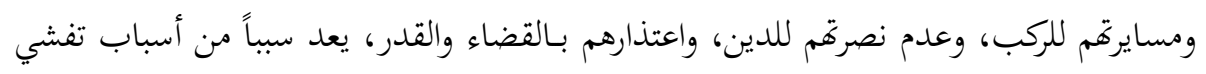

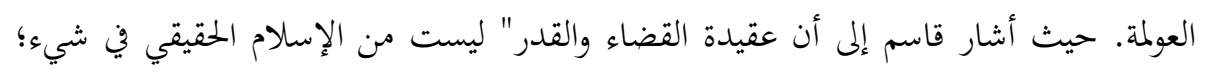

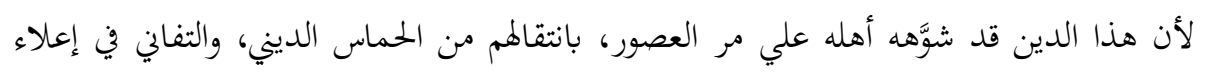
شأن العقيدة إلى الدعة والترف والشقاق فيما بينهم"(؟؟). فمهدوا السبيل للعولمة أن تنتشر بينهم. وقاسم بذلك ينتقد ويخاطب كل مسلم قد اندفع مع التيار العلموي متبعاً ومقلدًا، داعياً

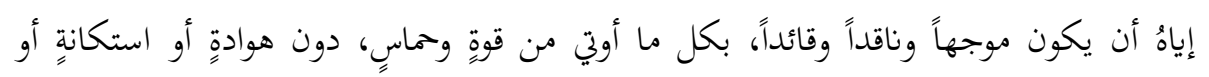
تواكلٍ؛ لأنه صاحب دين حق ورسالة حقة صالحة لكل زمان ومكان.

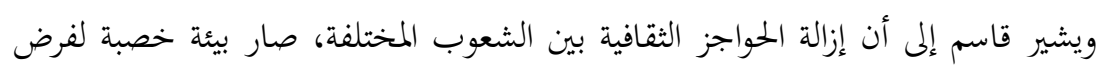

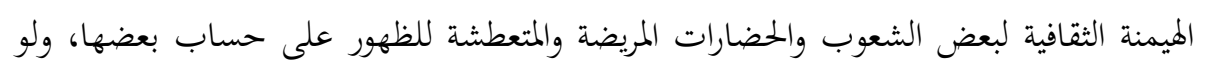

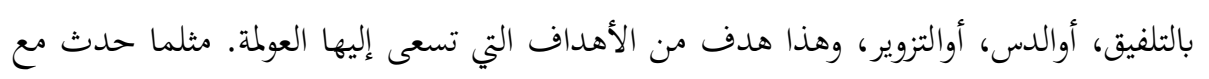

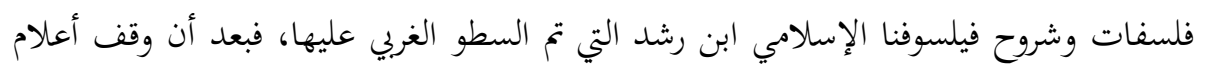

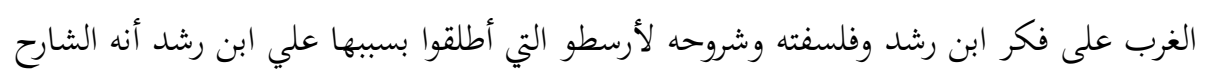

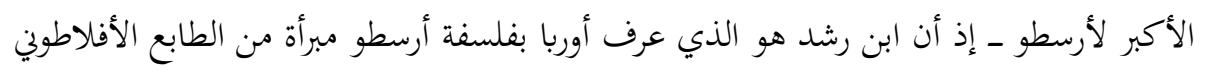

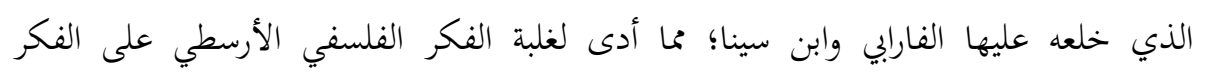

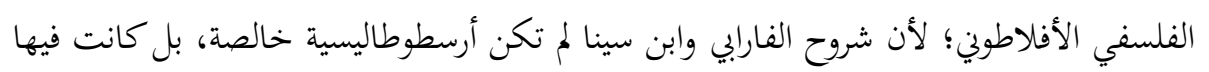

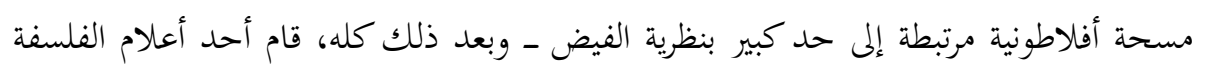

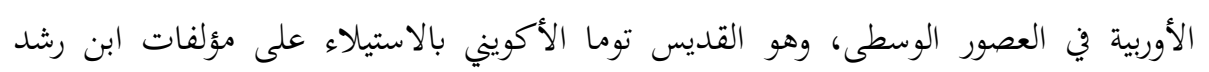

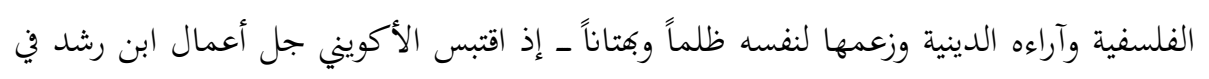


النفس وفي نظرية المعرفة وخلق العالم بل في غالبية موضوعات الفلسفة كلها كما في مسألة العلم الإلمي وحل مشكلة القضاء والقدر، ثم نسبها لنفسه في كتابه (الخلاصة اللاهوتية)(70).

وبناءاً عليه: فقد مجد الغرب توما الأكويني، زاعمين أنه مثثل الفلسفة الأوربية في العصور الوسطى، وأنه قد انتصر على الفكر الإسلامي حتى بدا في أعين بني ملته، الذين كانوا يجهلون

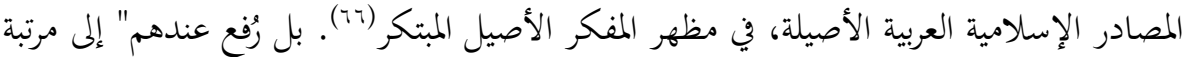

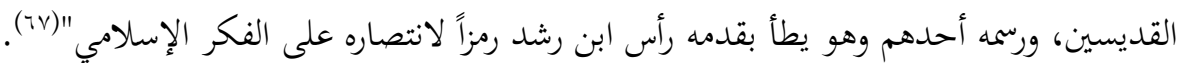
وهذا ما دعا البعض ك"رينان" الذي يعد من كبار المتخصصين في الدراسات الشرقية،

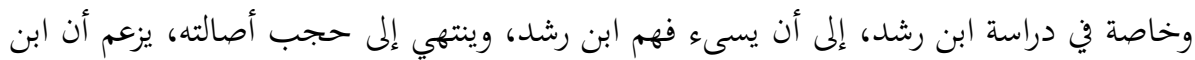

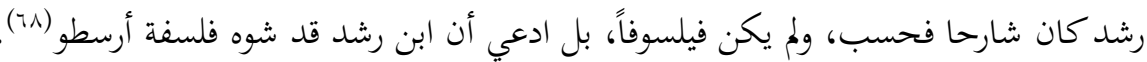
وهكذا ظهر توما الاكويني بين بني قومه بمظهر الفيلسوف النابغة، والمفكر العبقري، الذي خلعت عليه الكنيسة لقب القديس، ومنقذ المسيحية، وقاهر النزعة الإلحادية في أوروبا، حتى جاء محمود قاسم، فبين أن آراء الاكويني مصدرها إسلامي المنبع؛ فهي آراء ابن رشد وليسته إليست آراء

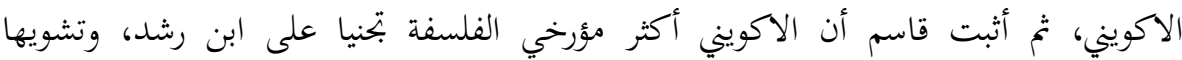
لفلسفته، حيث أخذ معظم آراء ابن رشد، واستعان بها في حل كبريات المشاكل الفلسفية، ثم

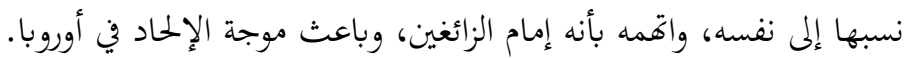

إلا أن قاسما قد أشار إلى أن رينان قد وقع في كثير من الأخطاء والتناقضات الواضحة في

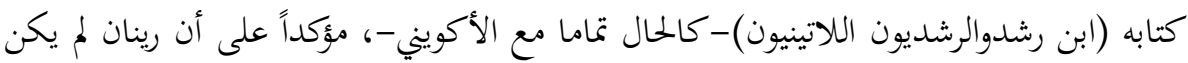

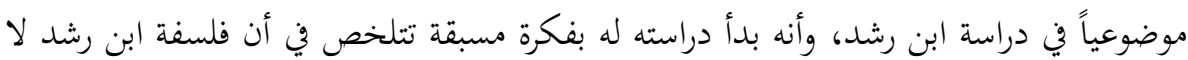
تختلف في شىء عن فلسفة كل من الفارابي وابن سينا، ويشارك رينان في ذلك المستشرق"مونيك"،

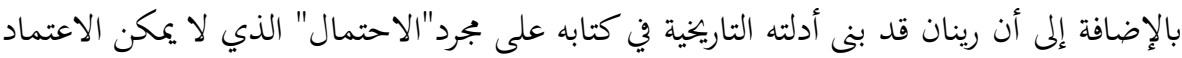

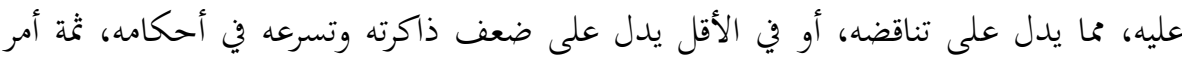

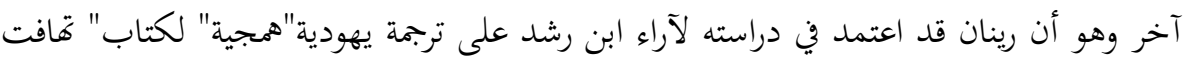

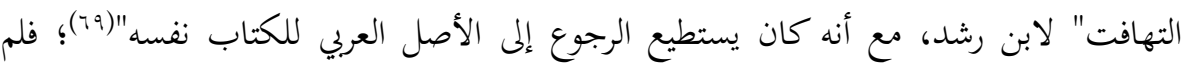
ينصف -هو الآخر-ابن رشد. 
وأشار قاسم أيضا إلى أن توما الأكويني" لم يفعل سوى أن أخذ آراء ابن رشد وزعمها

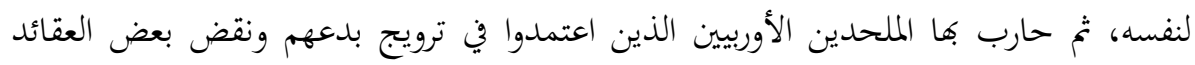

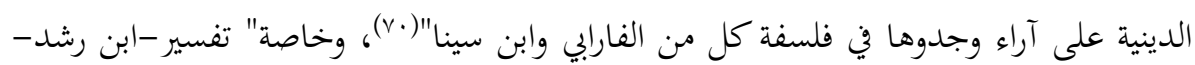
لنظرية العقل الفعال على نحو مبتكر - فـ -هو نفس التفسير الذي استحوذ عليه توماس الأكويني

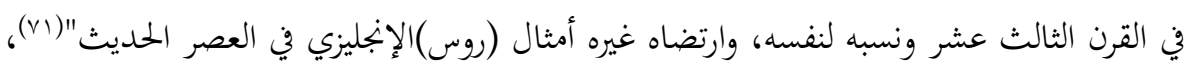
وهي النظرية التي قلبت رأساً على عقب، وجهة نظر الفارابي وابن سينا، وكانت ذريعة إلى تمجيد

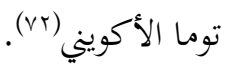

وقد تعجب قاسم من التوافق العجيب بين وجهات نظر ابن رشد والأكويني، وسير الأكويني على نفس النمط والعرض الذي ارتضاه ابن رشد، حيث يقول:" لقد وجدانا أوجه شبه فيه تدعو إلى الدهشة في الألفاظ والمصطلحات، فضلاً عن المنهج والفكرة"(vr).

ثم ازدادت دهشته" أعني قاسم" عندما انتهي توما الأكويني إلى نفس النتائج التي انتهى

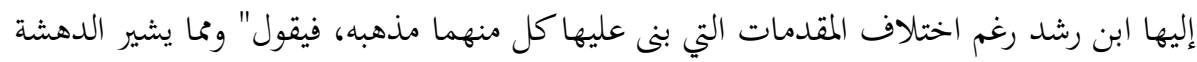
حقاً أن توما الأكويني بنى نظرياته في إثبات وجود الله تعالى على فكرة التفرقة بين الممكن التهن

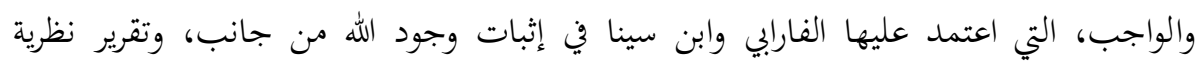
الفيض من جانب آخر؛ في حين أن فيلسوف قرطبة رفض هذه التفرقة واعتمد على فكرة العناية

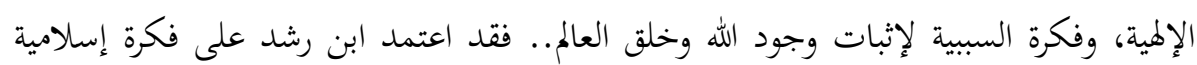

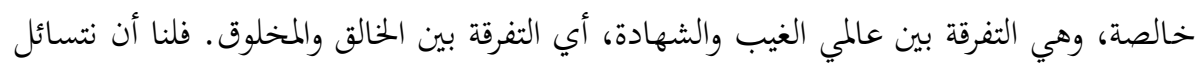
إذاً كيف أمكن لتوماس الأكوين(مع اختلاف المقدمات) أن يصل إلى نفس النتائج التي يقرها

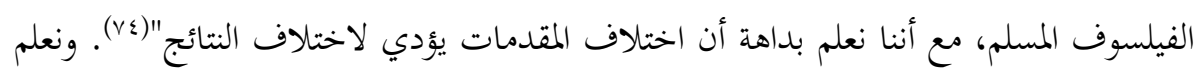

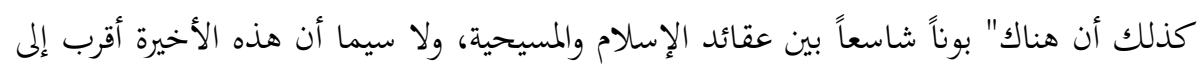

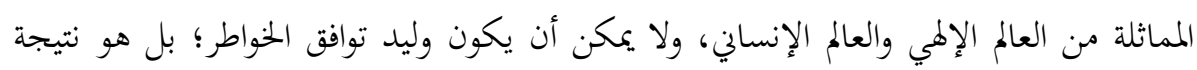
المحاكاة أو الترجمة الحرفية"(vo(v).

ويردف قاسم قائلاً " أنه قد حان الوقت للدارسين أن يكشفوا ستار الأوهام عن وجه هذا

$$
\text { الفيلسوف الذي غمط حقه في الشرق والغرب على حد سواء"(IT). }
$$


سواءً أكان ذلك بقصد من الغرب من أجل التشنيع على ابن رشد خاصة وعلى

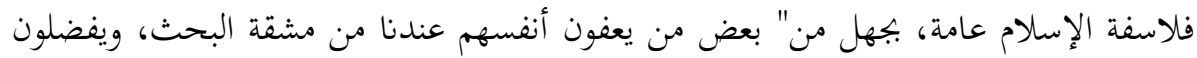

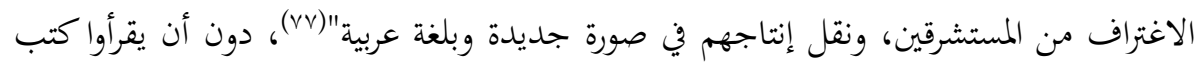

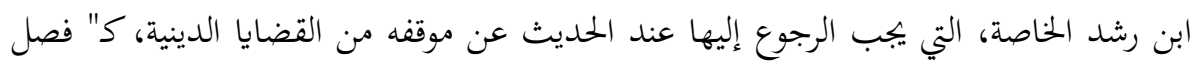

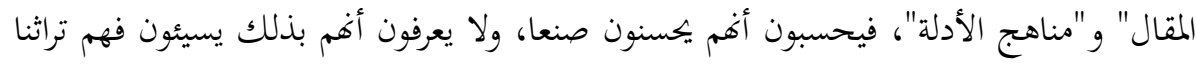
العربي، ويساعدون الغرب على فرض قيمه وهيمنة فلسفته وحضارته.

إلا أن زمن الأحقاد قد ولى" واختفي، أو كاد أن يختفي دون رجعة، وبات من العدل أن يعترف العالم الغربي، بما أفاده من فلسفة ابن رشد وشروحه لأرسطو، وأن يقر بما لحق فيلسوف

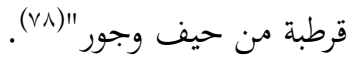

وأيضاً يشير قاسم إلى أن انتشار الجهل بين الناس يعد بيئة رحبة لظهور ما يسمى

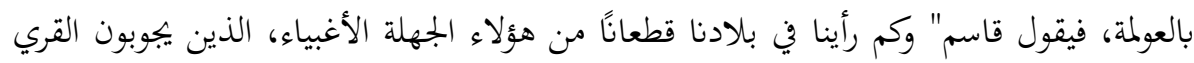

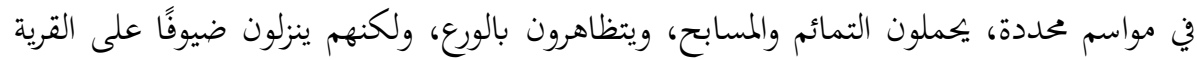

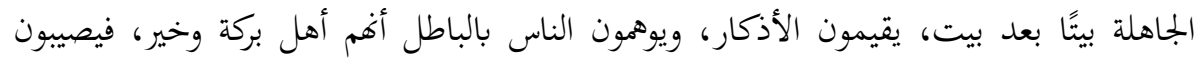

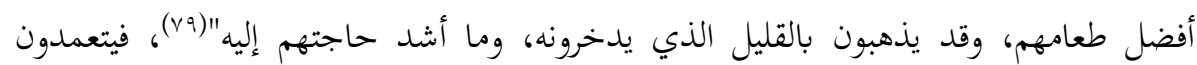

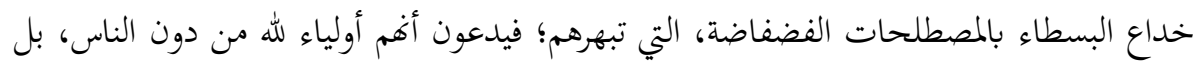

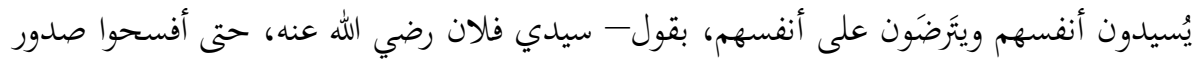

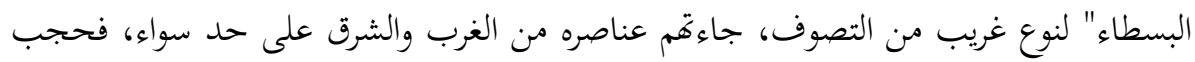

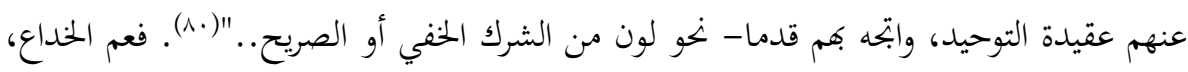
وتفشى الجهل، والتواكل، وسلبت الإرادة، وأصبح الجو مهيثًا لأن تؤَي العولمة أكلها.

ويشير كذلك إلي أن إهمال العناية بالإسلام ونشره من قبل أهله، كان سببًا في ظهور العولمة وفرض أرضيتها على المسلمين، فيقول" لقد أخبرخي صديقي، الدكتور محمد الفحام، أنه

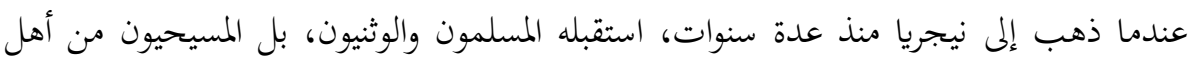
البلاد، بخير ما يستقبل به زائر، وكان فرح المسلمين به عظيمًا؛ إذ طالما سمعوا من إخواهم 
المسيحيين أفم يؤمنون بدين لا يعلمون شيًُا عن أهله، ولا زارهم أحد من علمائه، ولم تعن

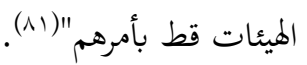

ويؤكد ما ذهب إليه قاسم، ما قاله الشيخ الإمام "أحمد الطيب" شيخ الجامع الأزهر

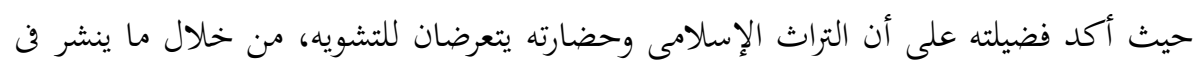

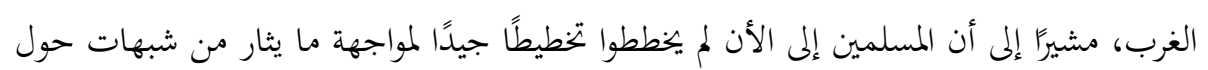

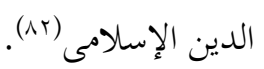
فنحن العرب مطالبون بالدفاع عن تراثنا وهويتنا، ومواجهة العولمة التي تدعو إلى الانفتاح،

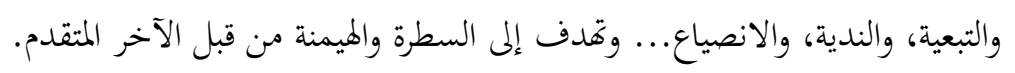

ثم يؤكد قاسم على أن ضعف الملوك وجهلهم، وعدم أخذهم بسبل التقدم، يعد سبباً من

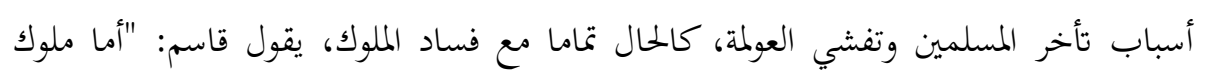

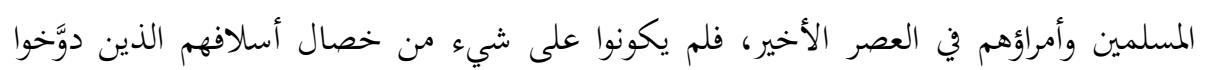

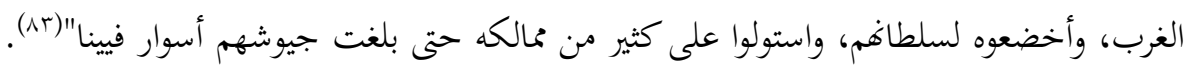

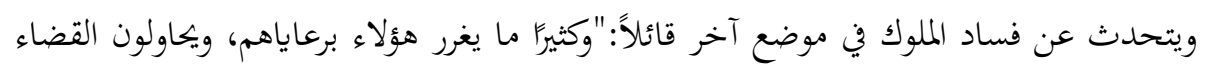

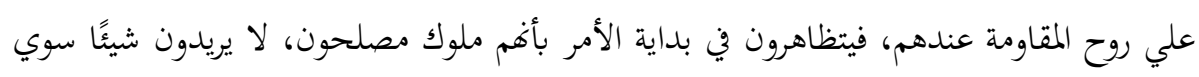

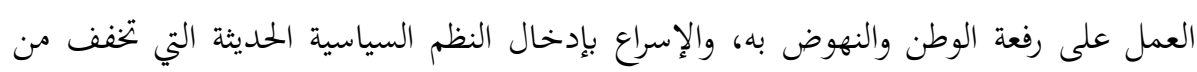

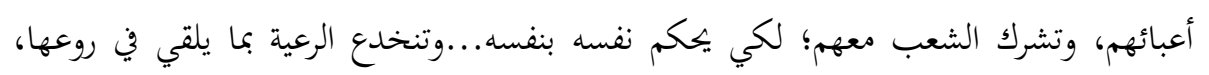

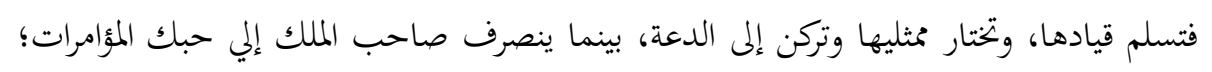

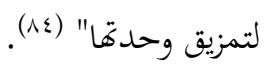

وهنا يرصد قاسم الأسباب التي تمكن الحاكم الفاسد من تخدير رعيته، ثم السعي لتشتيت

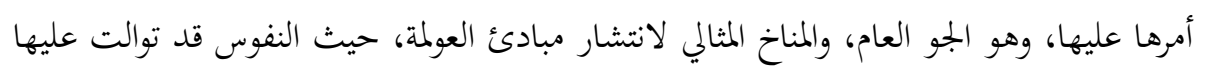

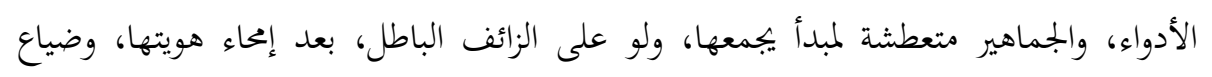

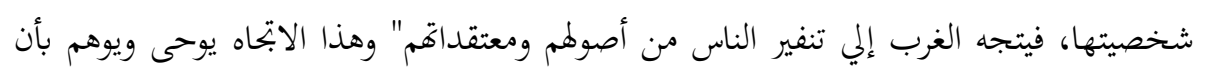

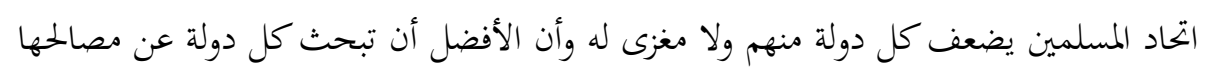

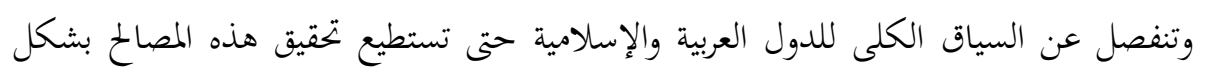


فعال.. مع محاولة استمالة هذه الدول نحو تطبيق النموذج الغربى في التنمية والثقافة على أساس أن التحديث يعنى التغريب، مع محاولة نشر بعض الكلمات والمصطلحات التى لا تتناسب فن الحقيقة

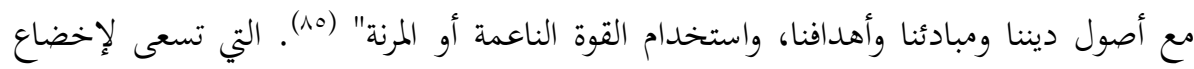

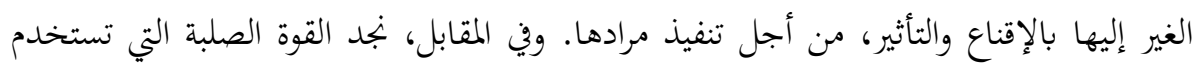

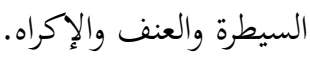

لقد استطاع محمود قاسم، أن يعايش عصره، ويثبت أنه يعي قضايا أمته، ويطلق صيحة

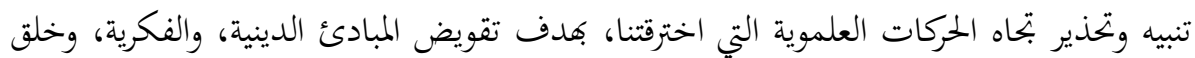

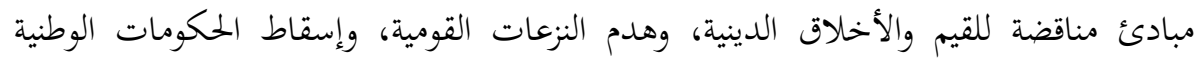

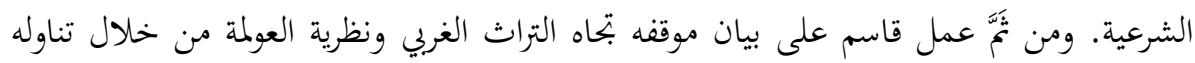
للتراث الغربي؛ فكانت كتابات محمود قاسم بمثابة الدفاع عن الذات التي اجتاحتها العولمة دون

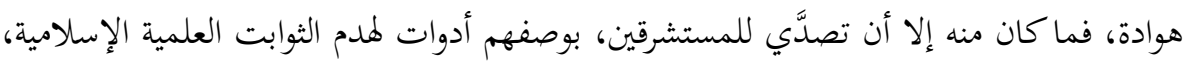

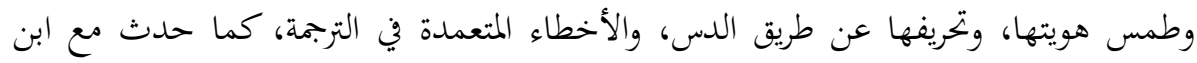
رشد.

واهتم قاسم بتوضيح ما للفلسفة الإسلامية من مكانة قوية تقوم على أساس ديني ثابت

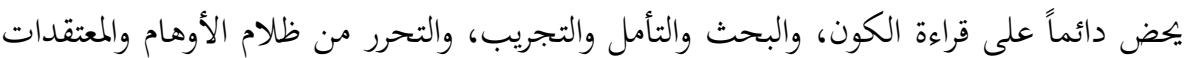

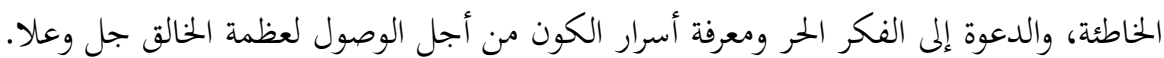

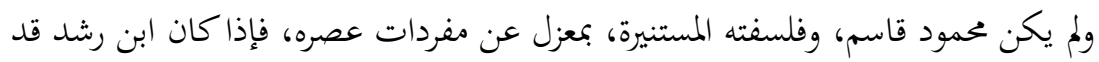

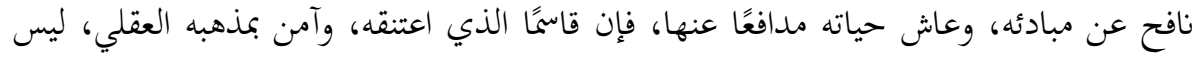

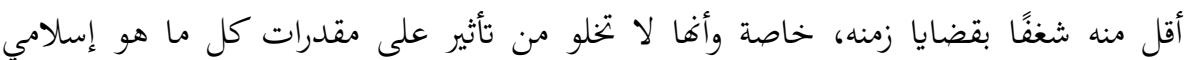
عروبي.

كما استطاع محمود قاسم بثقافته الإسلاميته وعقليته المرنة، أن يضع يده علي جراح أمة

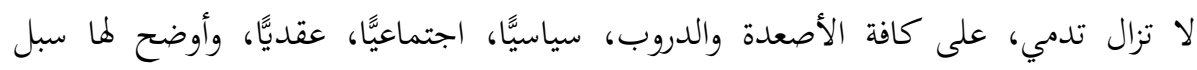

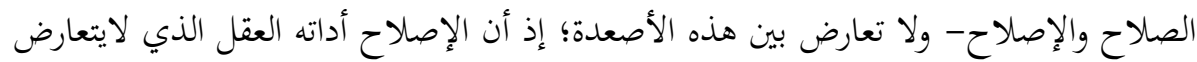

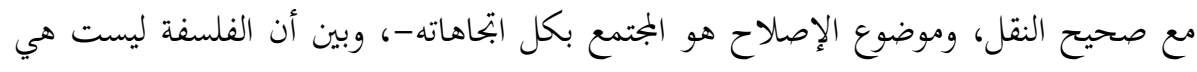


المتسببة في حالة التيه العقلي الذي درج عليه المسلمون، إنما العكس هو الصحيح، فالذين يعادون

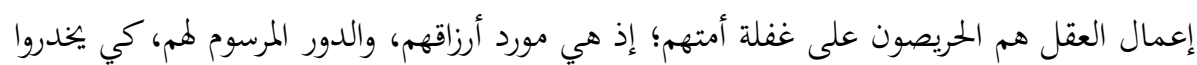
البلاد، ويخدعوا العباد، فلا تقوم لنا قائمة، ولا تعمر لنا دار، ولا يقر لنا قرار.

إن تفريط المسلمين فيما كانوا عليه من تسيُّد هو الذي مهَّد للغرب أن يخترق الأمة

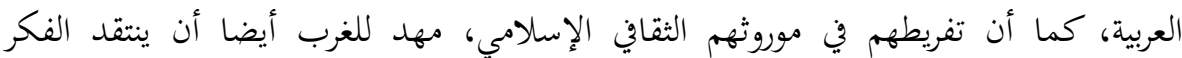

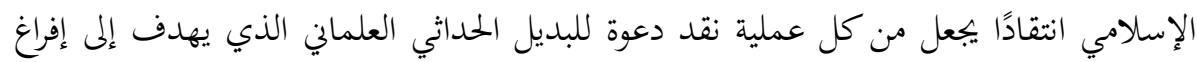

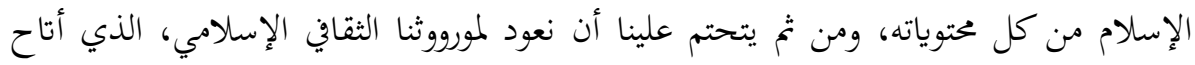

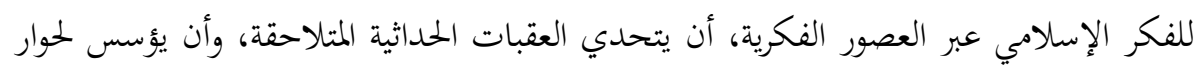
مستمر مع الحضارات الأخري.

ولابد من التجديد الفكري"لا الديني"، والتفاعل مع الفكر الإسلامي بروح الواقع وين

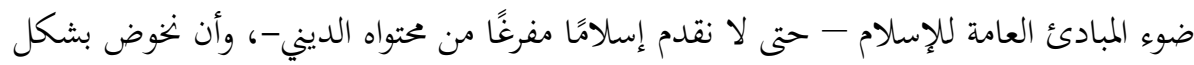

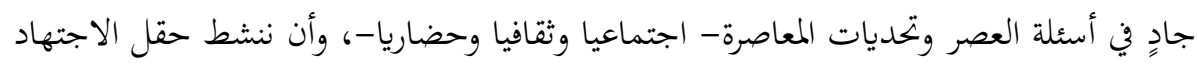

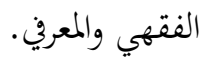

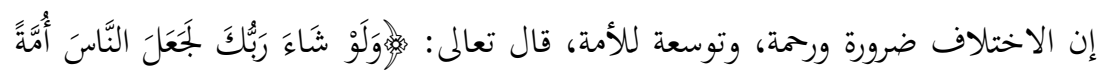

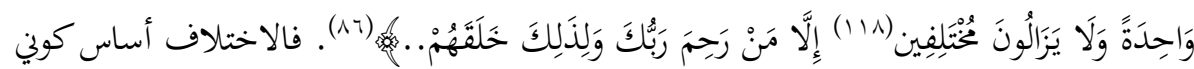

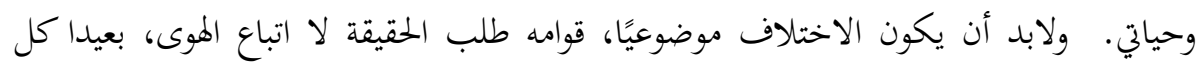

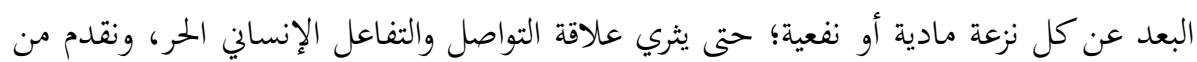

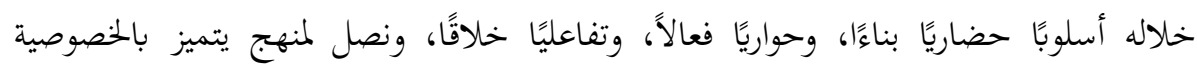

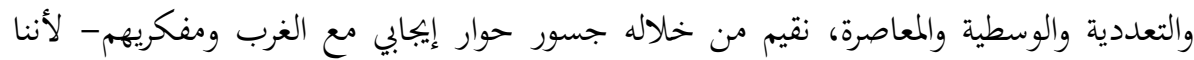

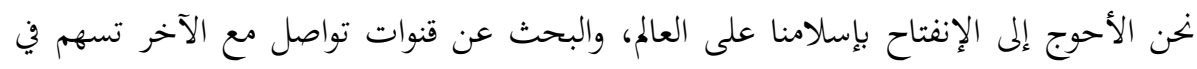

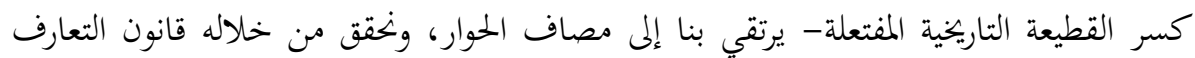
بين الناس، قال تعالى:

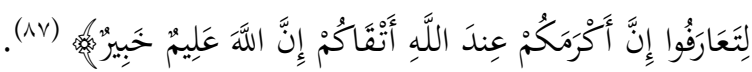


() ححمد بن مكرم بن منظور الأفريقي المصري: لسان العرب، دار صادر ،بيروت، ط:الأولى، (؟ / 99 (1)،

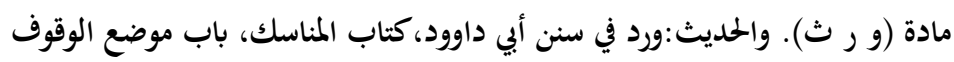

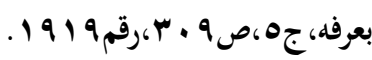
r) بحمد محمد الشحات غنيم عقيل: المؤتمر الدولي الحضارة والتراث العربي والإسلامي وإبداع وأصالة في

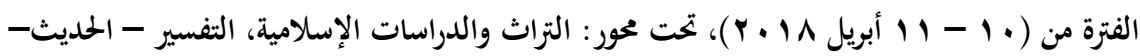

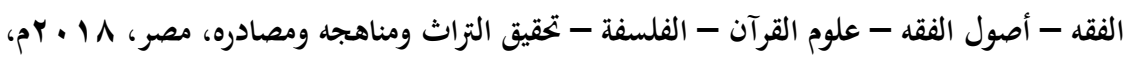
(ص: (

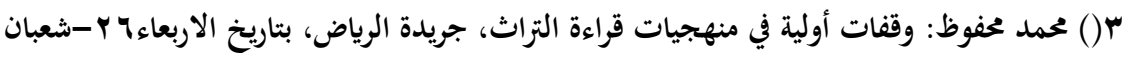

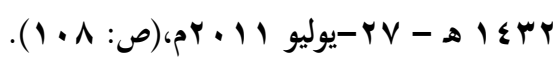

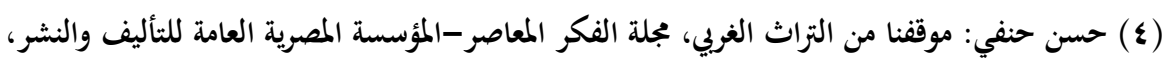

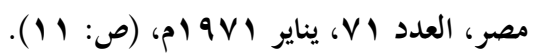

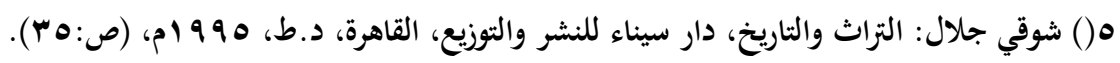

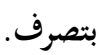

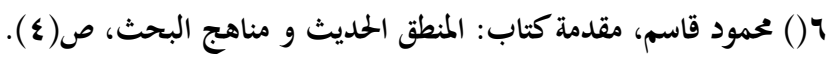

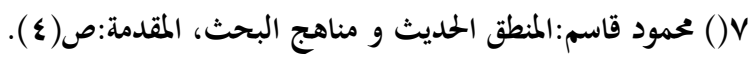

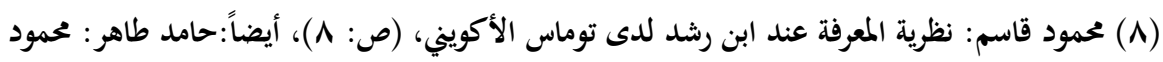

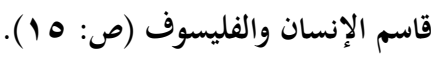

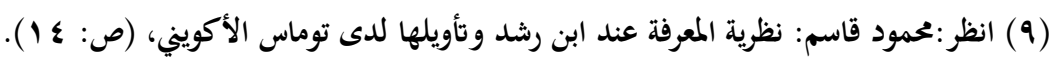

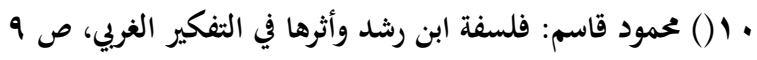

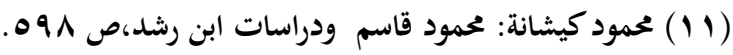

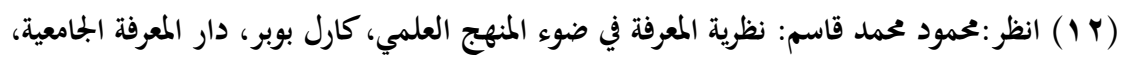

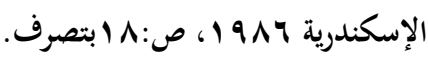

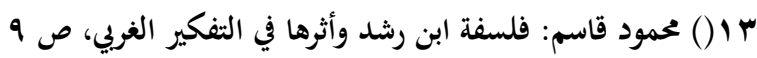

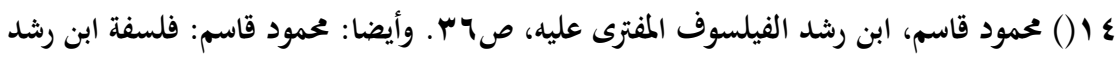

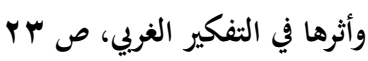

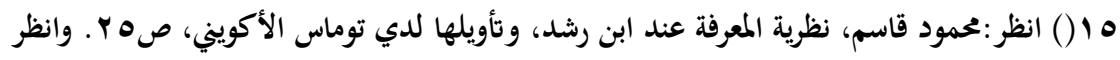

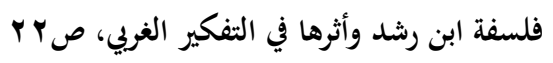




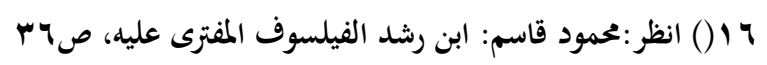

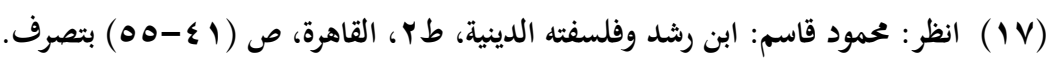

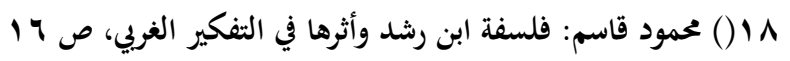

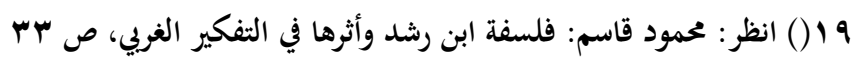

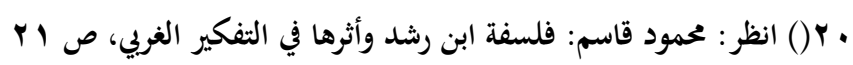

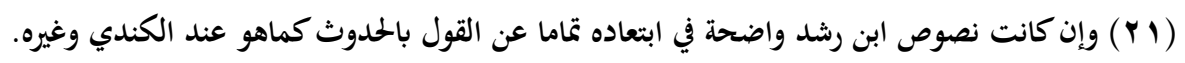

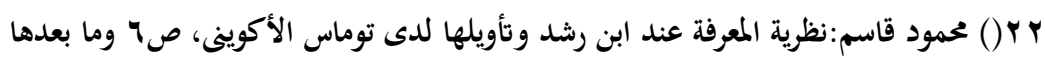

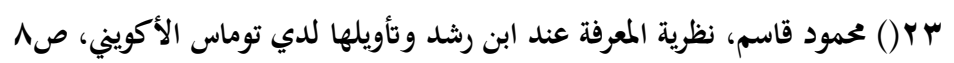

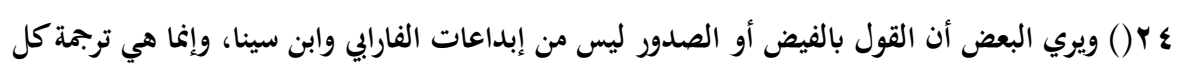

• P () محمود قاسم: فلسفة ابن رشد وأثرها في التفكير الغربي، ص 19

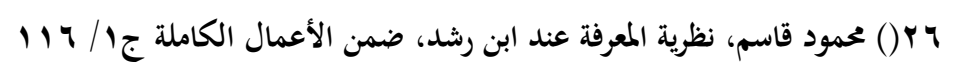

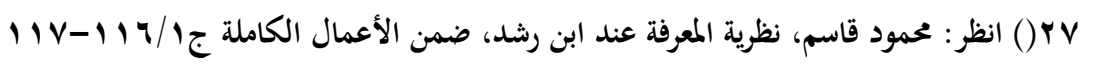

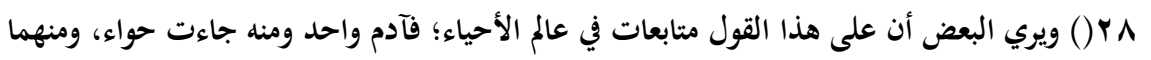
جاءت كل البشرية.

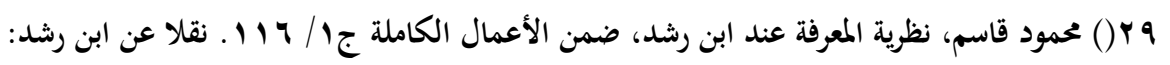

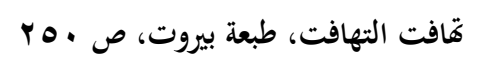

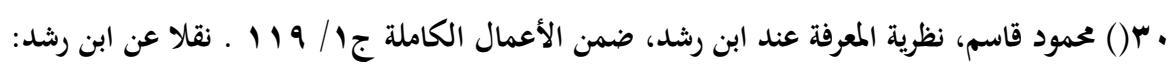

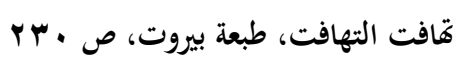

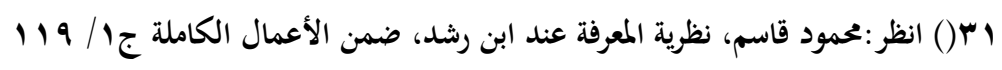

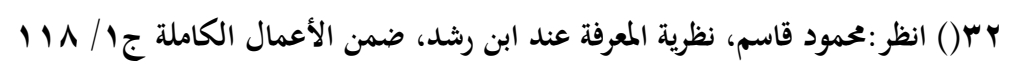

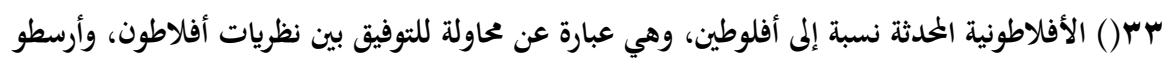

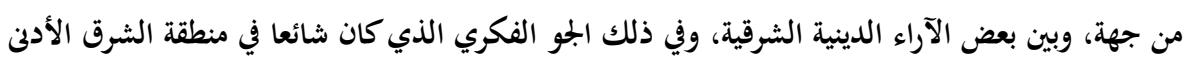
استطاعت الأفلاطونية المحدثة أن تكون من ثنائية أفلاطون التي تنطوي على "المثال" "والمادة" الفكرة القائلة بأن الله والطبيعة شيء واحد، وأن الإنسان والكون المادي ليسا سوى مظهر من مظاهر الذات الإلهية، وهو المذهب المعروف بمذهب "وحدة الوجود". محمد إبراهيم الفيومي، تاريخ الفكر الديني الجاهلي، ط: ع ، دار

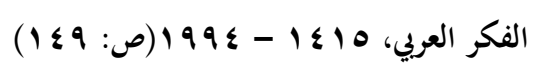

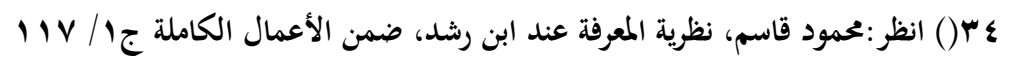

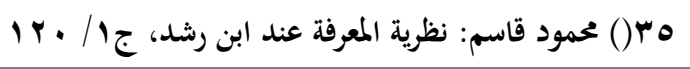




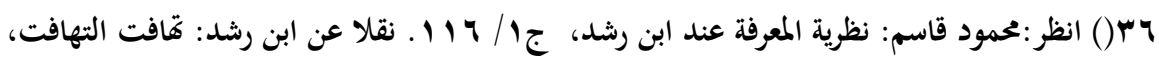

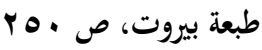

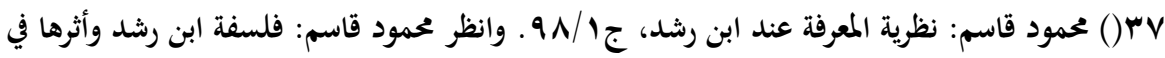

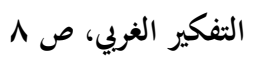

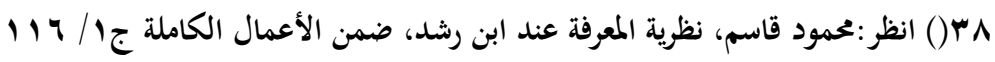

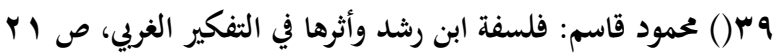

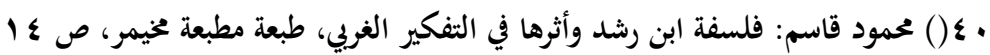

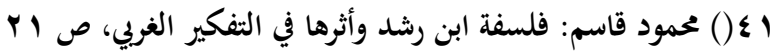

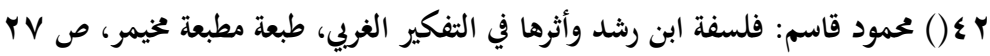

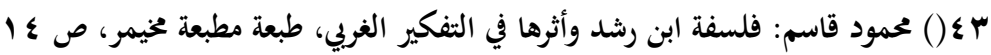

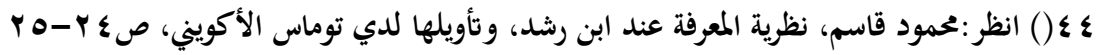

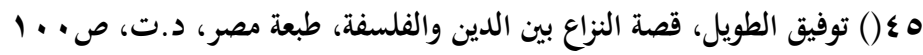

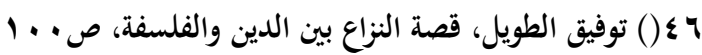

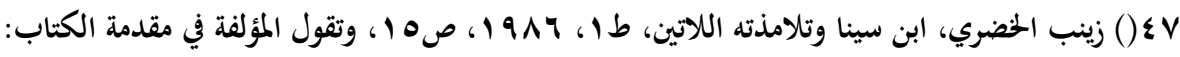

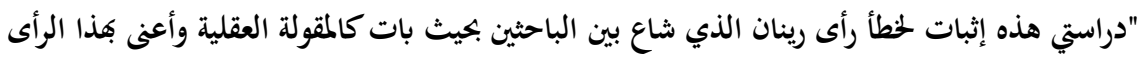

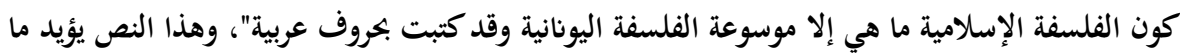
ذهب إليه محمود قاسم

1 \ () حسن حنفي: مقدمة في علم الاستغراب، مؤسسة الجامعية للدراسات والنشر ، طج، $10 \cdot 0,4+.9$

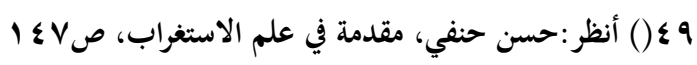
(• (•) انظر، محمود قاسم: نظرية المعرفة عند ابن رشد وتأويلها لدى توماس الأكويني، سلسلة في الدراسات

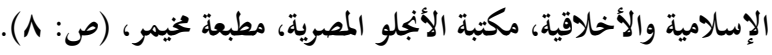

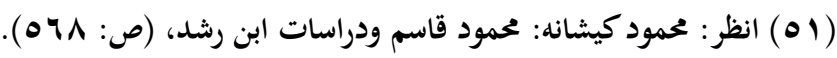
ror() محمود قاسم، في النفس والعقل لفلاسفة الإغريق والإسلام، مكتبة الأنجلو المصرية، الطبعة الثالثة، صVr

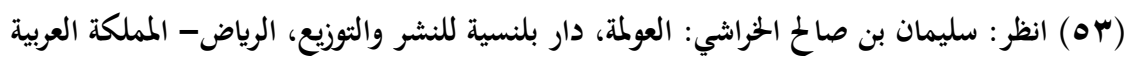

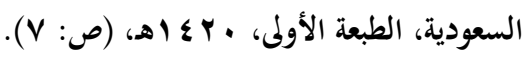

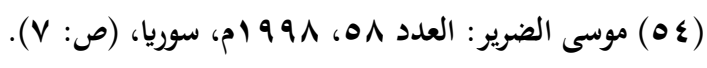




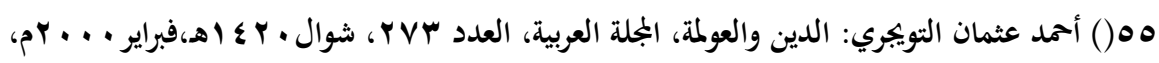
صی

צه() بربر علوي السادة: العولمة طريق الميمنة، مجلة الوعي الإسلامي، العدد 9 • ع ، رمضان ـ ب ع اهـ.

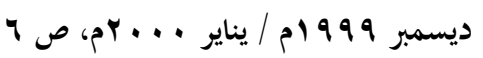

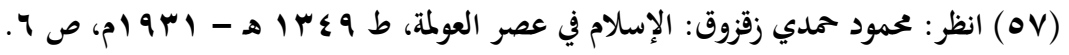

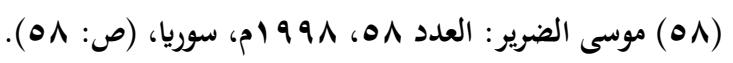

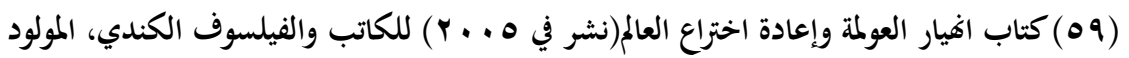

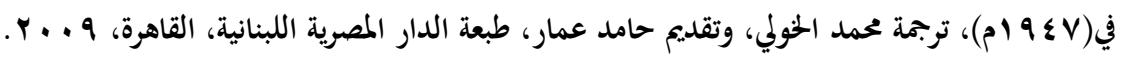

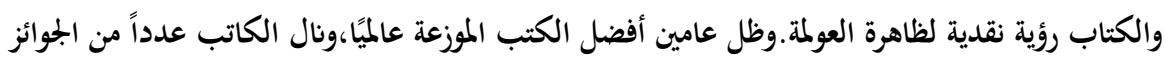
والأوسمة في كل من كندا وفرنسا وتشيلي. ( • ( ) انظر: جون رالستون سول:إفيار العولمة وإعادة اختراع العالم، ترجمة محمد الحولي، وتقديم حامد عمار،

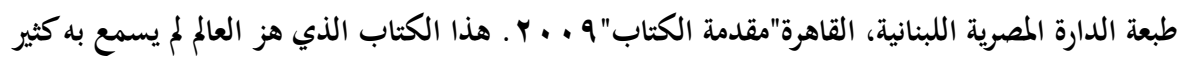

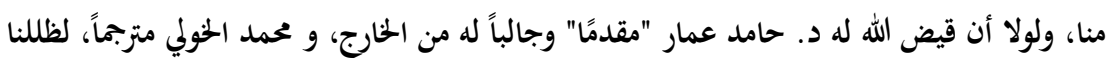

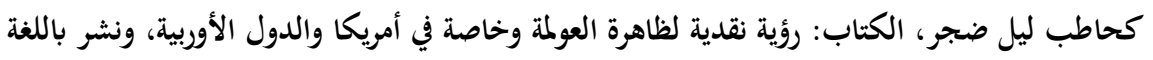

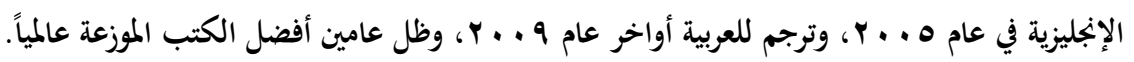

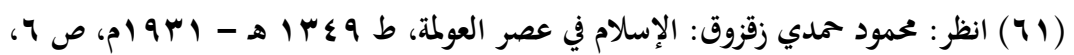

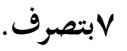

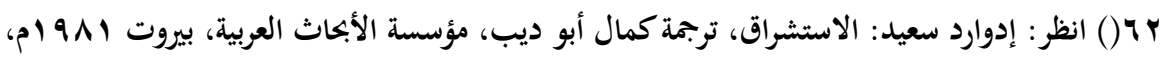
ص ص 19 وما بعدها

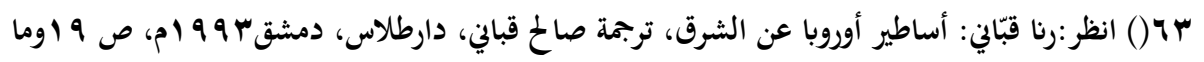
بعدها

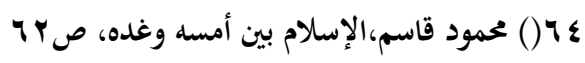
ه 1 () انظر : محمود قاسم: فلسفة ابن رشد وأثرها في التفكير الغربي، محاضرة بجامعة أم درمان الإسلامية،

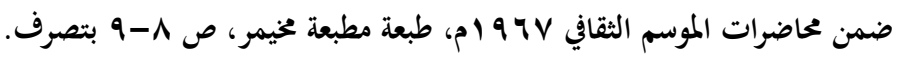
צ

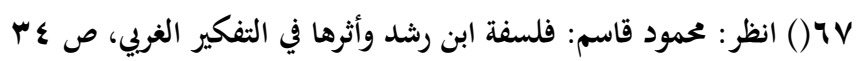

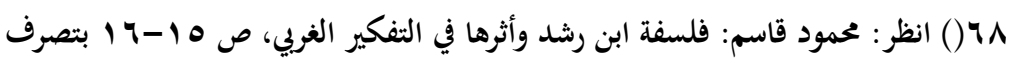

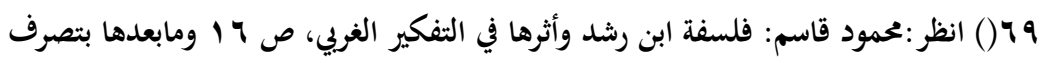

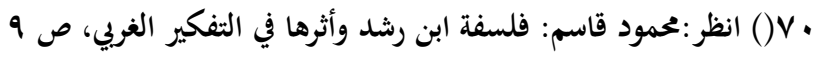




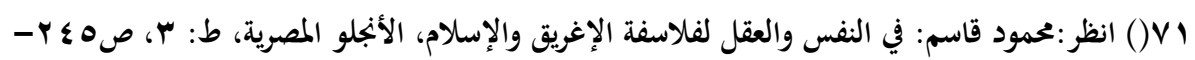

9 () انظر :محمود قاسم: فلسفة ابن رشد وأثرها في التفكير الغربي، ص 9 ()

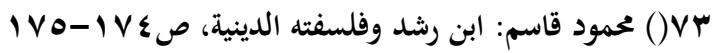

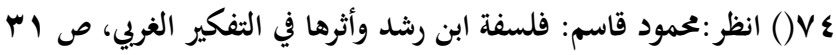

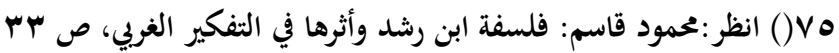

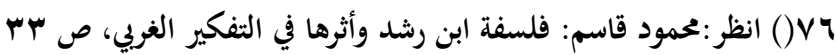

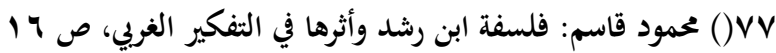

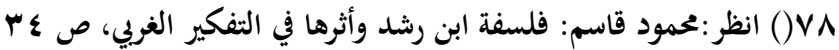

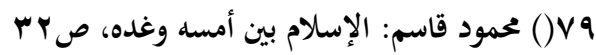

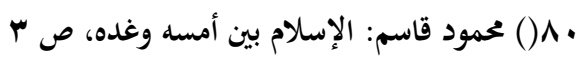

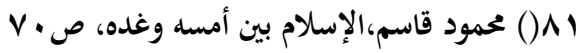

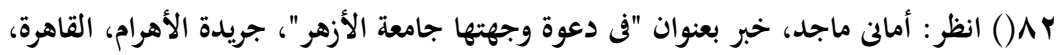

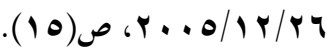

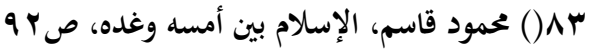

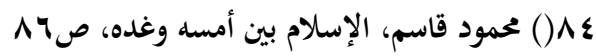

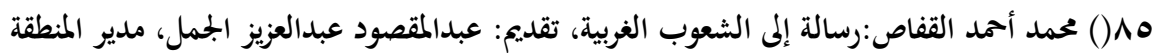

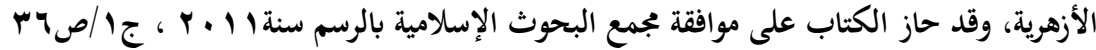
צ^)( سورة هود: الآيتان:(1) NV 
(1) محمود قاسم: فلسفة ابن رشد وأثرها في التفكير الغربي، محاضرة عامة، جامعة أم درمان

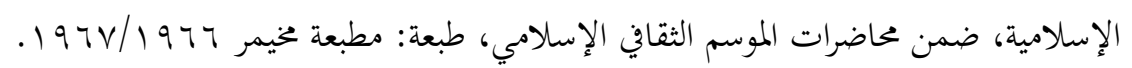

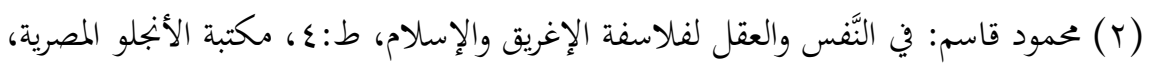
عام 979 ام.

(r) محمود قاسم: نظرية المعرفة عند ابن رشد وتأويلها لدى توماس الأكويني، مكتبة الأنجلو

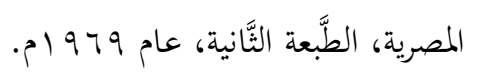

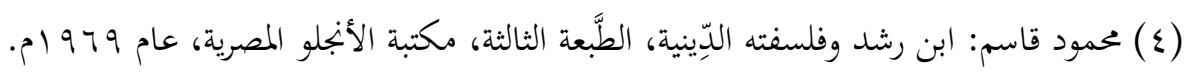

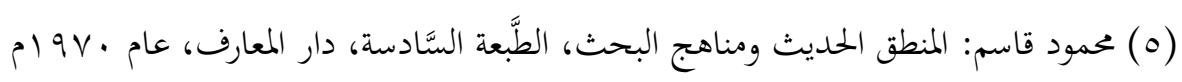

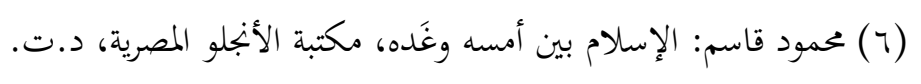
(V)

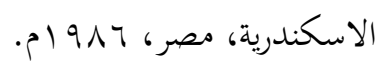

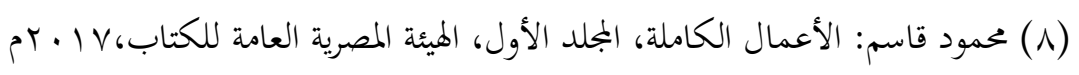

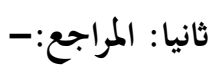

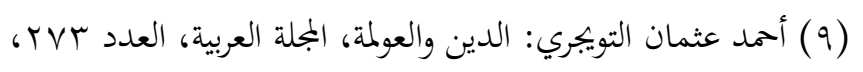

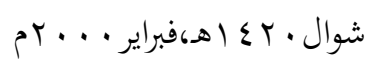

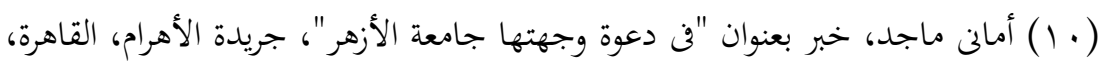

$$
\text { r. . o/ T r/rT }
$$

(1) إدوارد سعيد: الاستشراق، ترجمة كمال أبو ديب، مؤسسة الأبحاث العربية، بيروت

1919

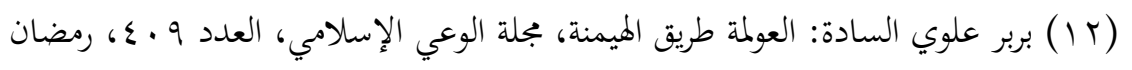

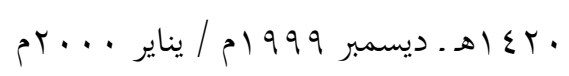

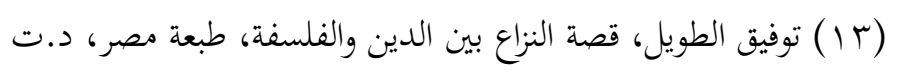




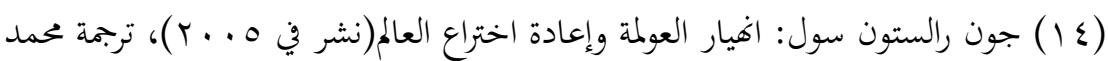
الخولي، وتقديم حامد عمار، طبعة الدار المصرية اللبنانية، القاهرة، و ـ . ب.

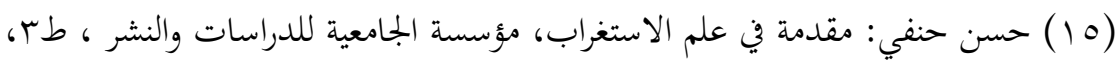
r..

(7 (1) حسن حنفي: موقفنا من التراث الغربي، مجلة الفكر المعاصر-المؤسسة المصرية العامة

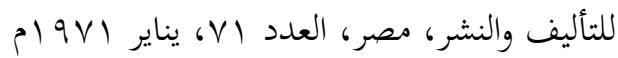

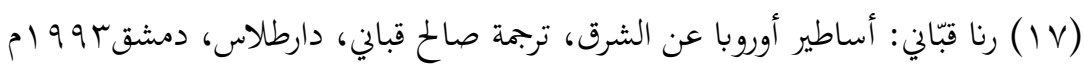

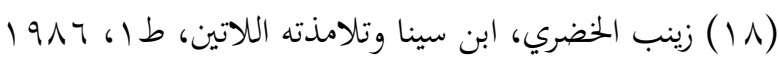

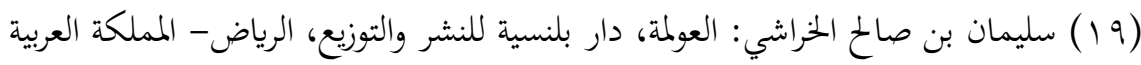

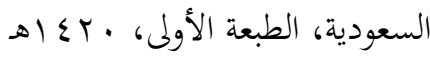

(Y) شوقي جلال: التراث والتاريخ، دار سيناء للنشر والتوزيع، القاهرة، د.ط، 990 ام م.

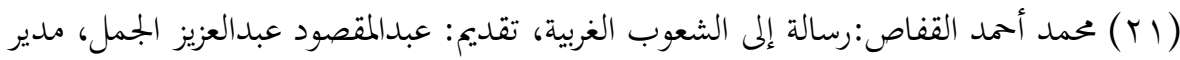

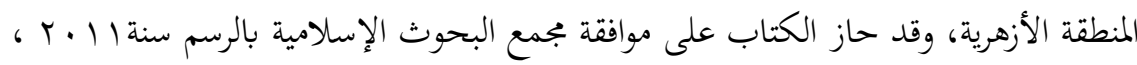
(YT) (Y) محمد بن مكرم بن منظور الأفريقي المصري: لسان العرب، دار صادر ،بيروت، ط:الأولى

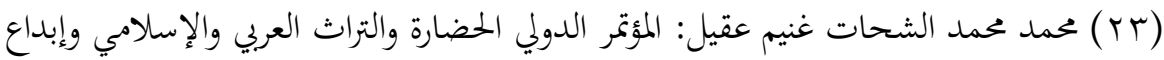

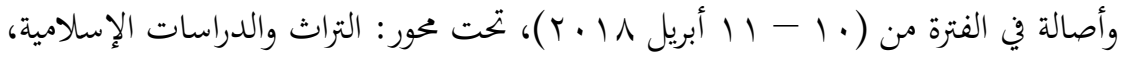
التفسير - الحديث- الفقه - أصول الفقه - علوم القرآن - الفلسفة - تحقيق التراث ومناهجه

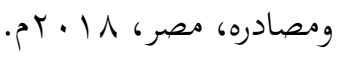

(Y (Y) محمد محفوظ: وقفات أولية في منهجيات قراءة التراث، جريدة الرياض، بتاريخ

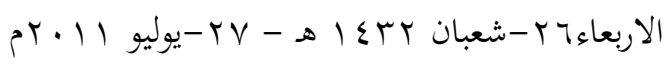

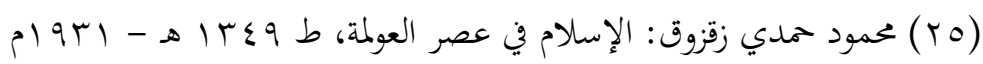

